\title{
فاعلية الذكاءات المتعددة على مستوى الأداء المهارى لخطوط اللعب فى كرة القدم

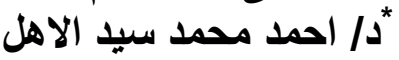

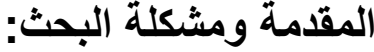

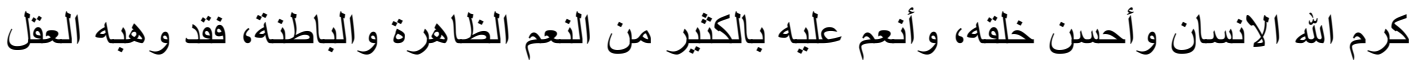

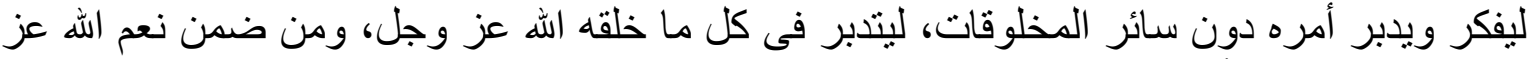

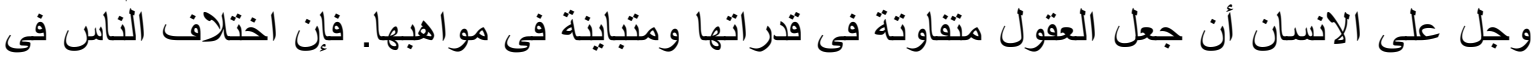

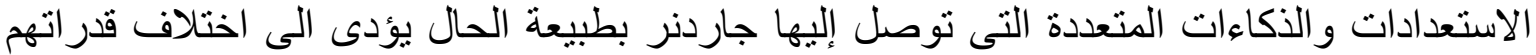
على العمل و الكسب وتحصيل العلم، وبناء عليه يختلفون فى واجئ الجباتهم ومسئولياتهم.

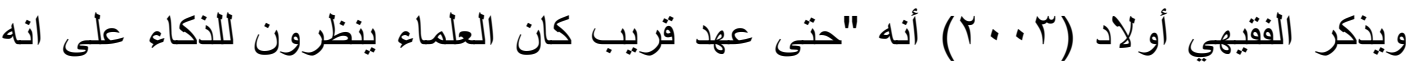

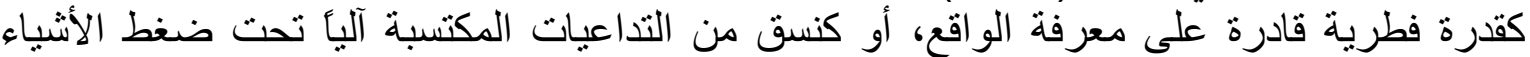

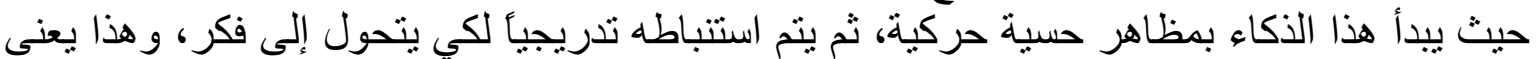

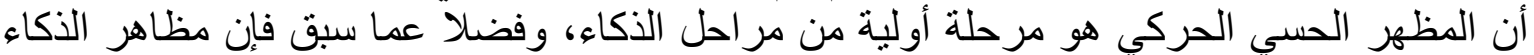

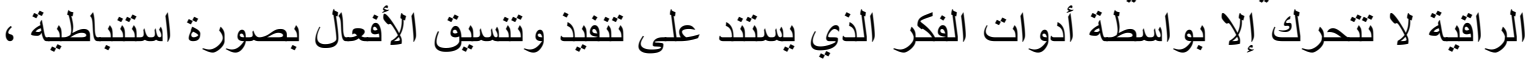

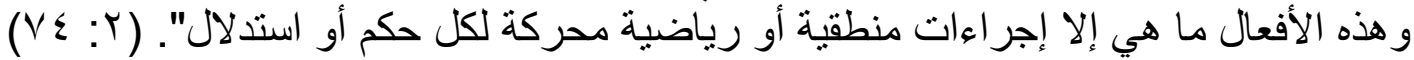

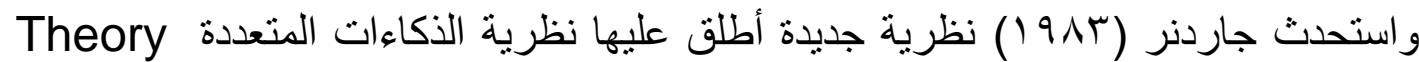
Multiple Intelligences

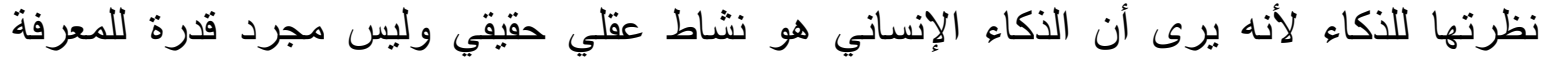

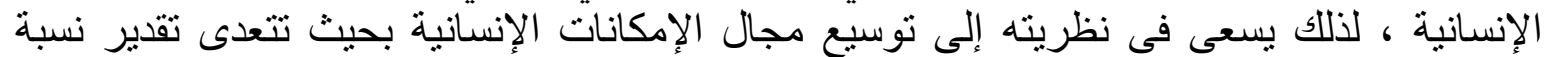

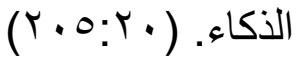

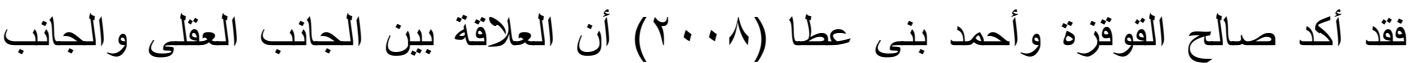

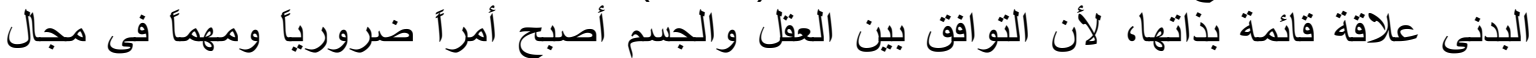

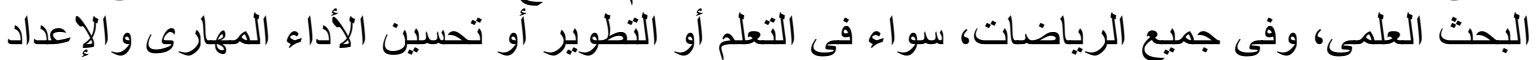

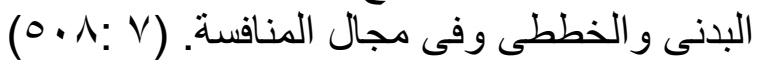

وقد لخص آرمسترنج (Armstrong,1994) الأفكار الرئيسية في نظرية الذكاءات المتعددة

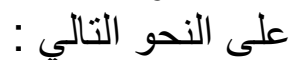

كل شخص يمنلك سبعة ذكاءات (أضيف إليها حديثًا الذكاء الثامن).

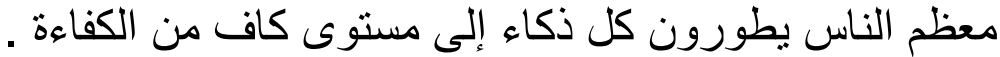

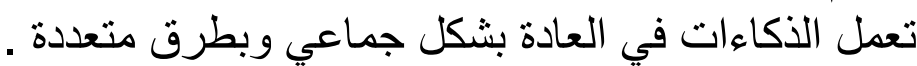
هنالك وسائل عديدة ليكون المتعلم ذكياً ضمن فئة معينة .

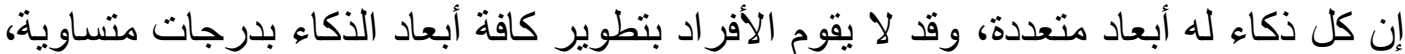

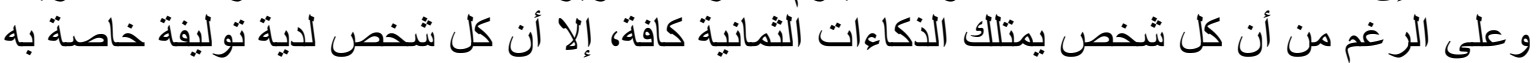

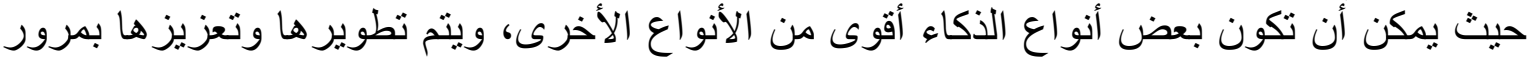

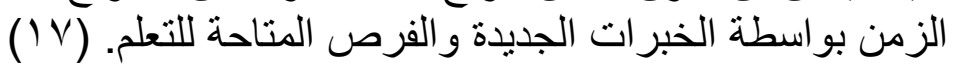

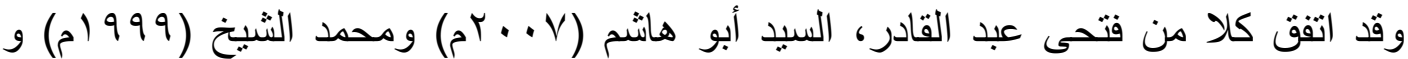
(999 Alick, Dave ومتنوعة قابلة للنمو والتنمية والتغير وكل شخص لدية خليط فريد لمجموعة ذكاءات نشطة يمكن

* مدرس بقسم نظريات وتطبيقات الألعاب الجماعية وألعاب المضرب ـ كلية التربية الرياضية - جامعة العريش. 
التعرف عليها وتتميتها كما ان استعمال احد انواعها يمكن ان يساهم فى تنمية وتطوير نوع اخر.

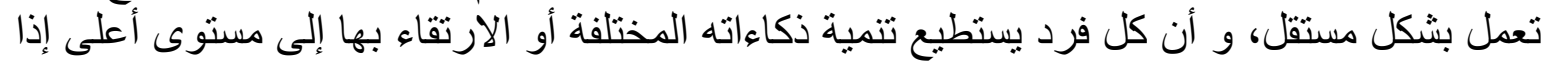

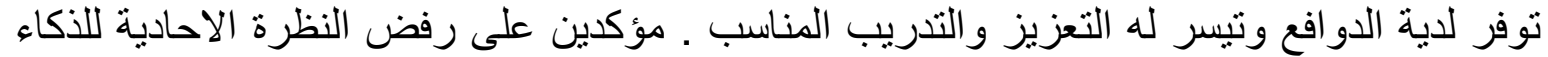

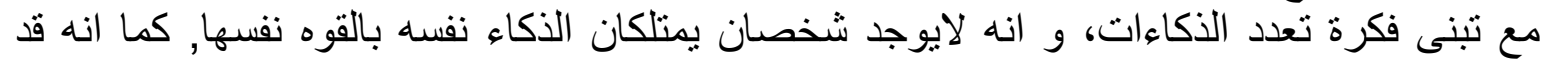

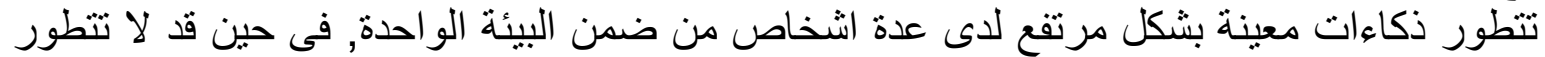

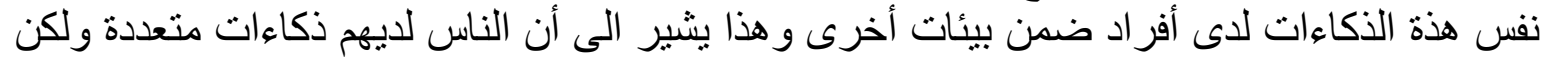

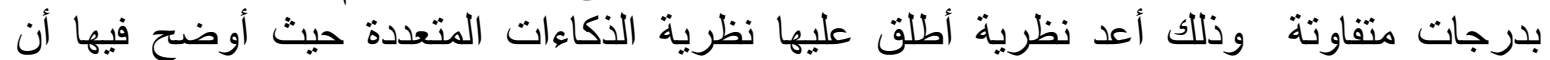

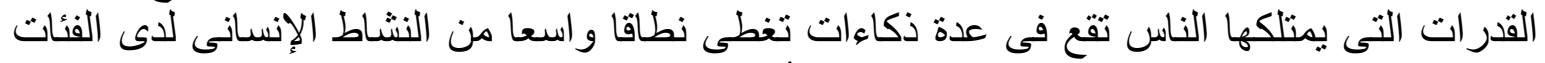

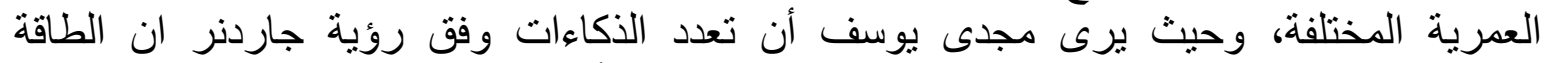

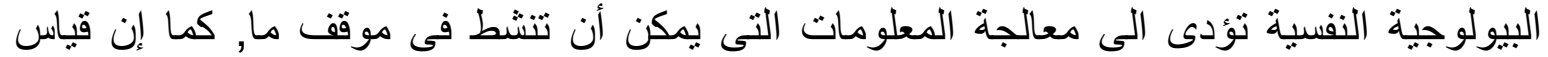

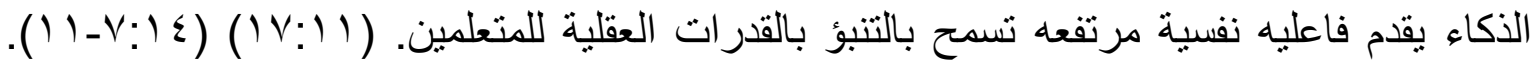
$(\varepsilon: 1 r)(0 r: 117)$

وقد ظهرت العديد من الوسائل التى يمكن من خلالها تطوير مستوى الذكاءات المتعددة التى

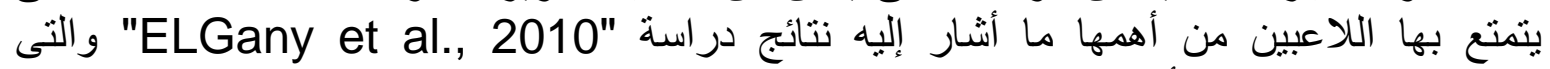

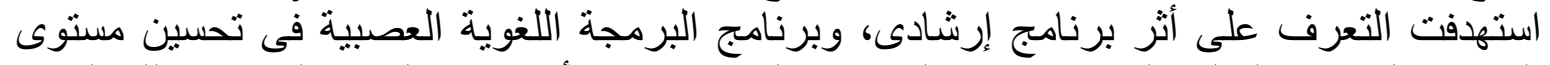

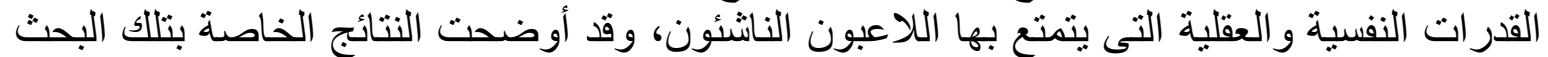
على فاعلية البر امج المقدمة فى تحسين مستوى القدرات النفسية والعقلية للاعبين الناثنئين. (9 (:؛

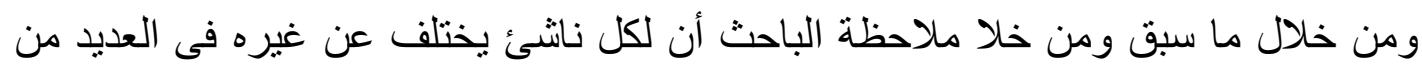

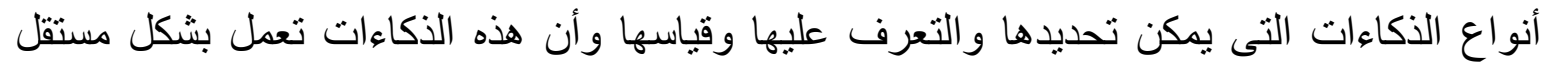

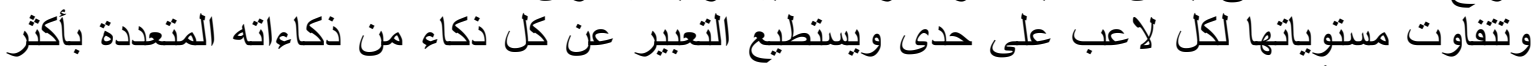

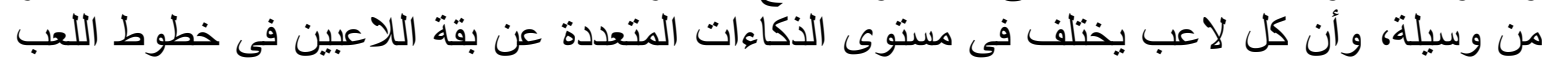

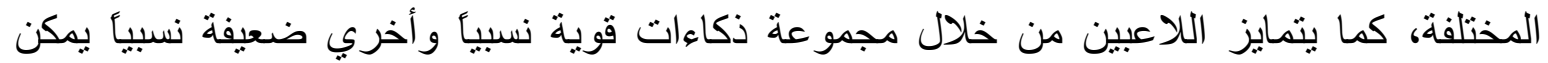

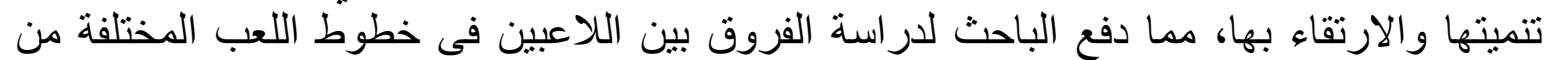
خلال الذكاءات المتعددة وارتباطها بالمستوى المهارى لخطوط التعاء اللعب المختلفة.

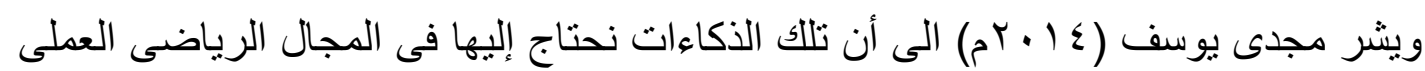
و التطبيقىو التى تتمثل فى الآتى :-

ا- الأكاء اللغوي اللفظى Linguistic Intelligence:

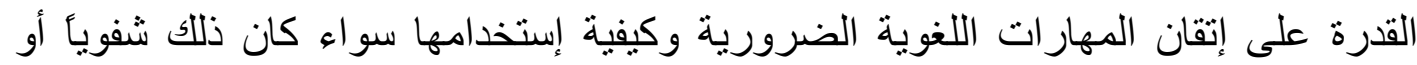
تحريريأ بفاعلية فى المجال الرياضى, وايضا ايجاد مهارات الاتصال الفعال التى تساعد في فهر

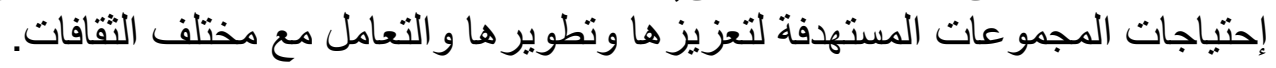

\section{rogical Mathematical Intelligence: الذكاء المنطقى الرياضي}

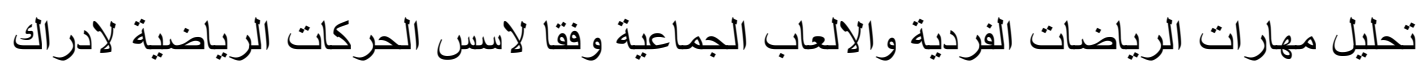

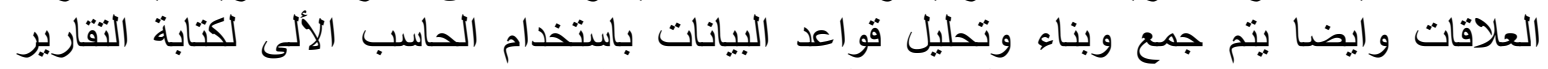

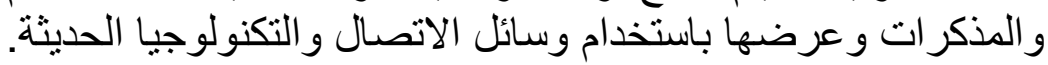

r- الذكاء البصرى المكاني Visual Spatial Intelligence

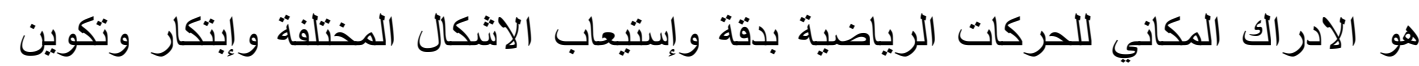

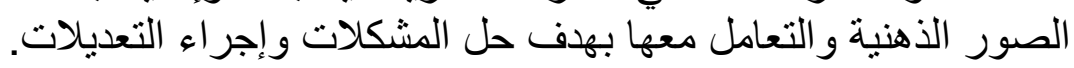


هو مقدرة الجسم للتعبير عن الافكار و المشاعر و وأداء النماذج التطبيقية للمهار ات الحركية فى

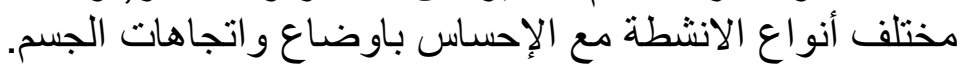

هـ الأكاء الموسيقى الإيقاعى Musical Intelligence

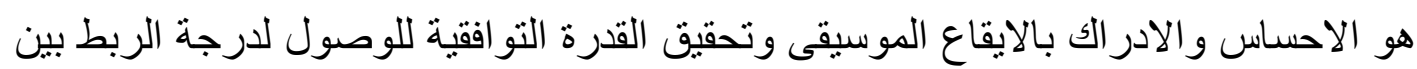

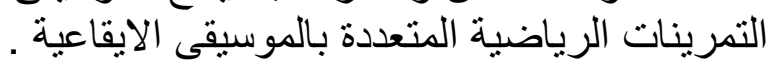

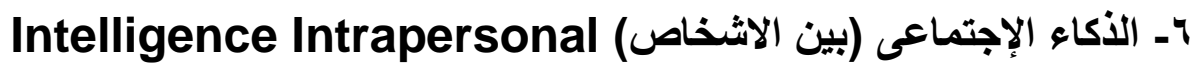

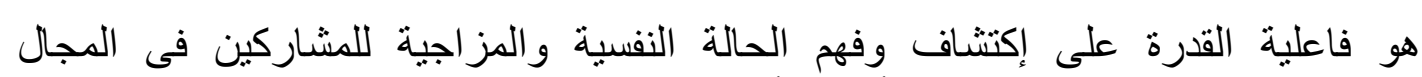
الرياضى و العمل الجماعى لتفعيل وتطبيق أداب وأخلاقيات المهنة.

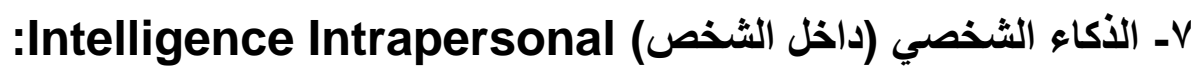

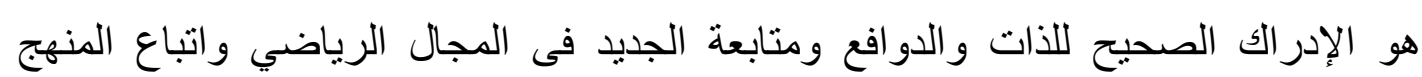
العلمى وإختيار البدائل المناسبة لحل المشكلات .( (1:9 - • ( )

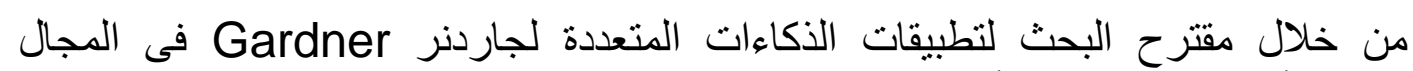

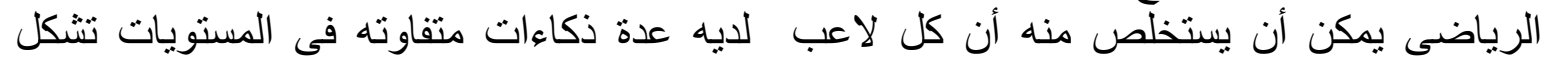

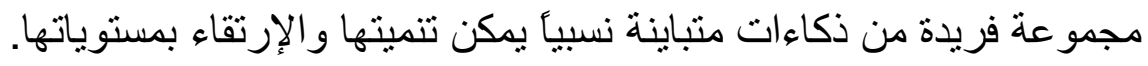

هاف البحث:

يهذف البحث إلى التعرف على فاعلية الذكاءات المتعددة على مستوى الأداء المهارى لخطوط

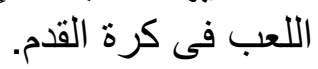

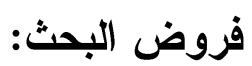

اـ توجد فروق ذات دلالة احصائية بين خطوط اللعب فى مقياس الذكاءات المتعددة للاعبى

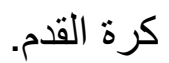
r- يوجد إرتباط ذات دلالة إحصائية بين الذكاءات المتعددة والاختبارات المهارية قبد البحث.

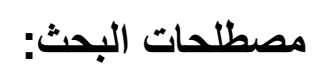

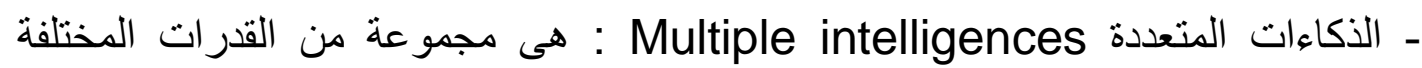

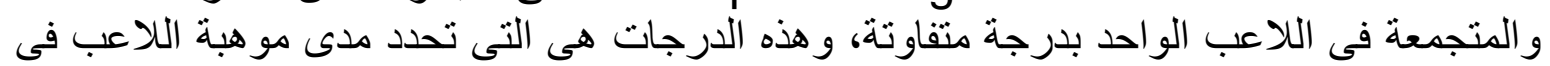

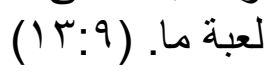

\section{الاراسات السابقة : مابة}

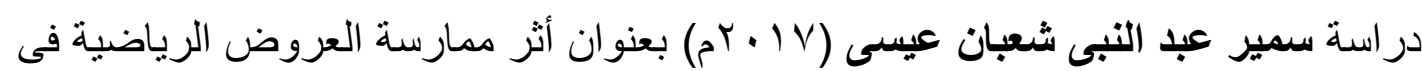

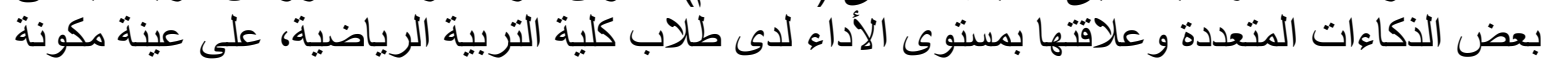

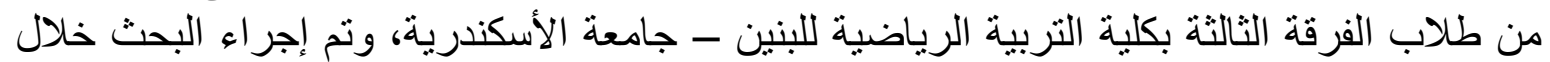

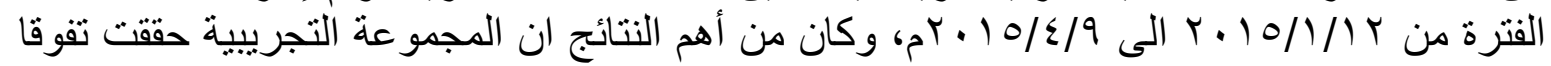

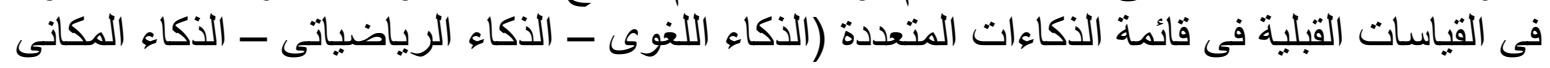

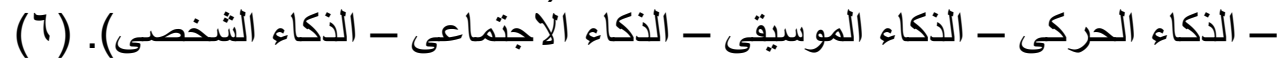




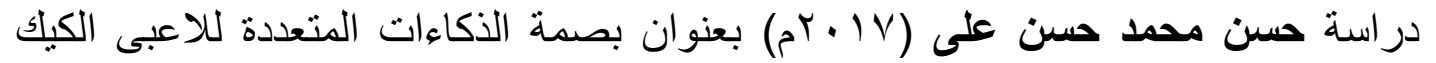

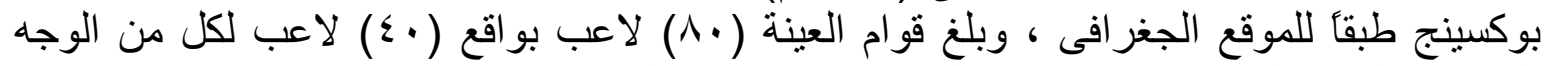

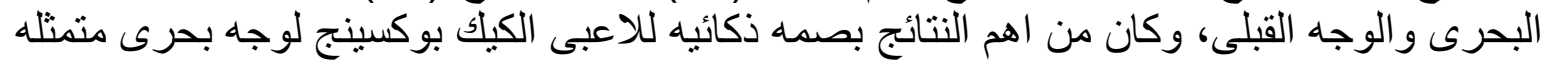

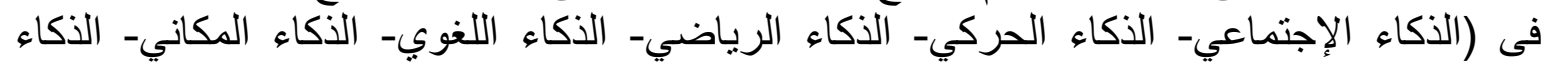

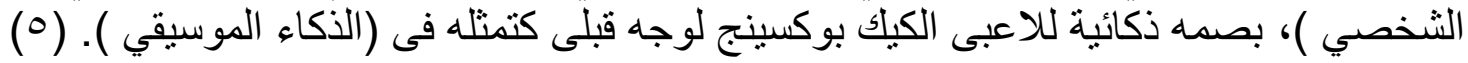

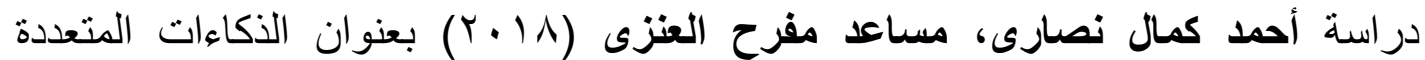

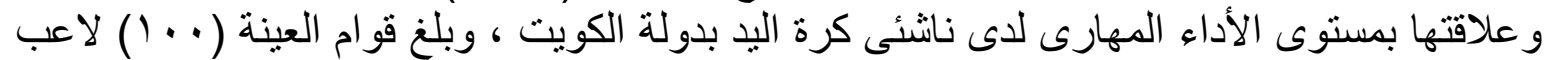

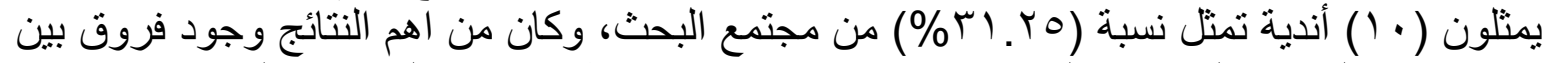

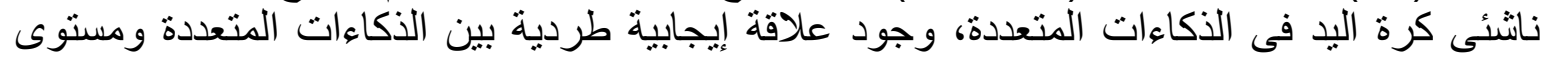

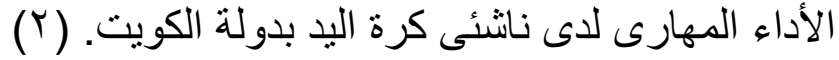

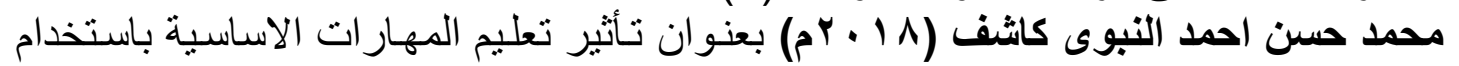

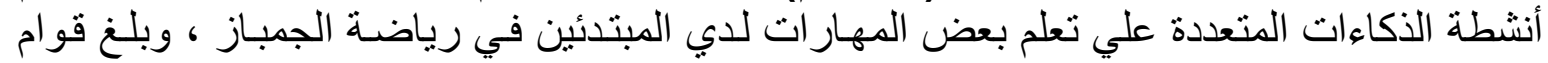

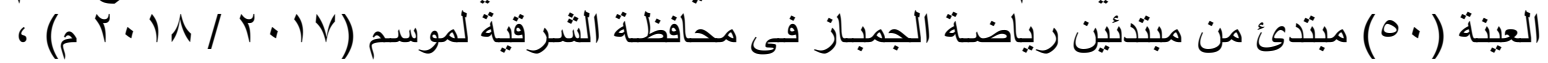

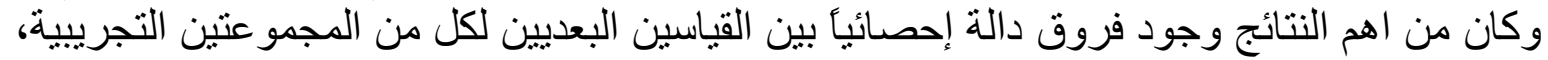

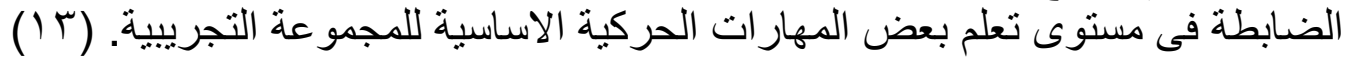

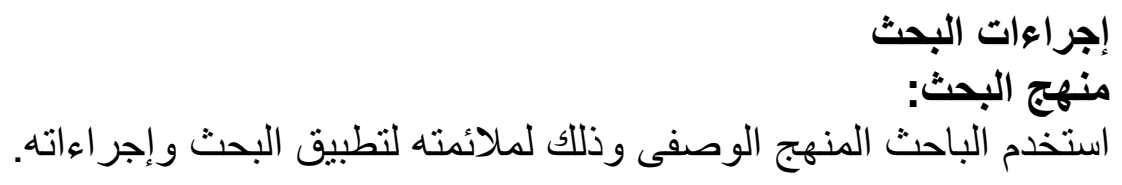

المجال المكانى:

بعض أندية الوجه البحرى فرق تحت (9 ( ) سنة و المشاركين فى بطولة المناطق و القطاعات.

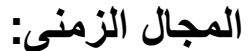

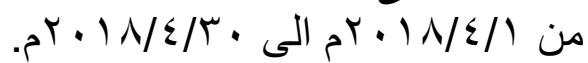

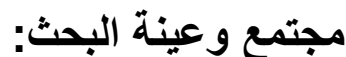

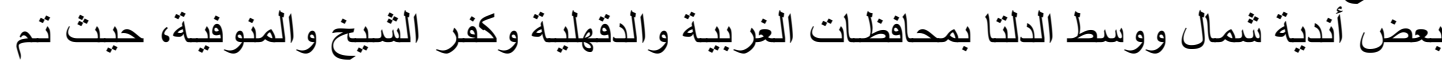

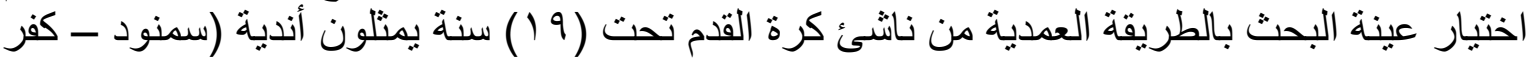

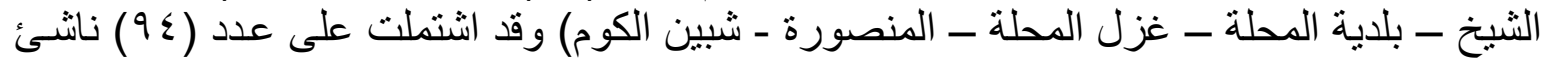
تحت 19 سنة.

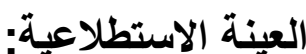

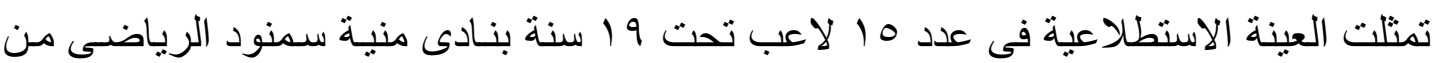

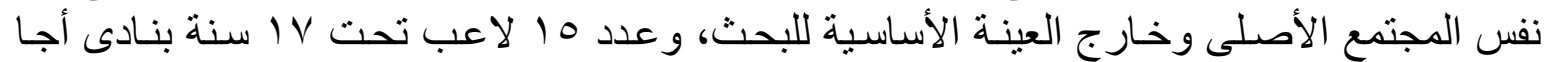

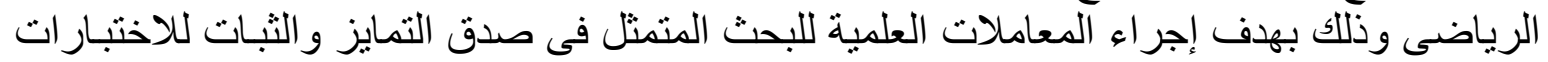

\section{شروط اختيار العينة: - اء}

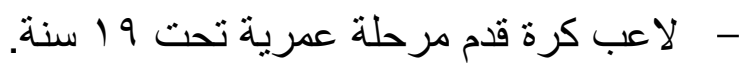

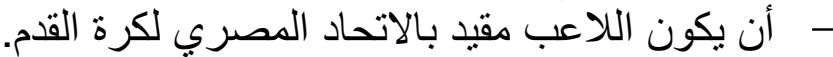

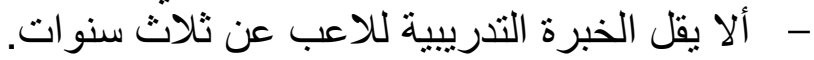
- - أن يكون اللاعب منتظم فى التدريب. 


\section{جدول (1)}

توزيع العينة الأساسية طبقا لمراكز اللعب المختلفة بالأندية عينة البحث

\begin{tabular}{|c|c|c|c|c|c|c|c|c|}
\hline 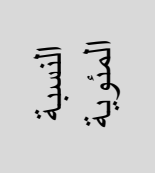 & 京. & 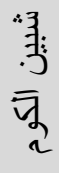 & $\overbrace{: 0}^{\bar{g}}$ & $\begin{array}{l}: 4 \\
\overline{3} \\
\overline{3}\end{array}$ & $\frac{7}{3}$ & 羿 & 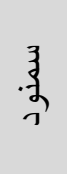 & \\
\hline$\% \backslash r . V V$ & Ir & 1 & $r$ & r & r & r & r & حر اس المرمى \\
\hline \% & rv & $\Lambda$ & $\varepsilon$ & V & 7 & 0 & V & لاعبى خط الدفاع \\
\hline$\% r \leq . \leq V$ & $r r$ & $r$ & 0 & $\varepsilon$ & $\varepsilon$ & $r$ & $\varepsilon$ & لاعبى خط الوسط \\
\hline \%rr.s. & rr & $r$ & r & $\varepsilon$ & $r$ & 7 & $\varepsilon$ & لاعبى خط الهجوم \\
\hline$\% 1 \ldots$ & $9 \leq$ & 10 & 10 & IV & 10 & IV & 10 & الإجمالى \\
\hline
\end{tabular}

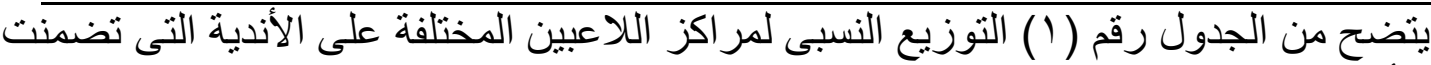

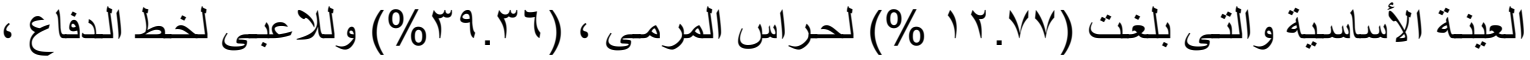

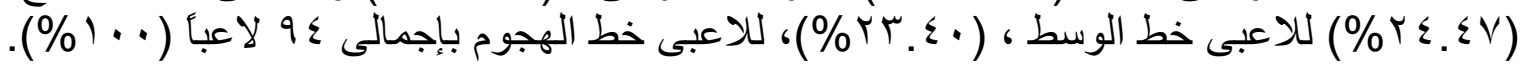

$$
\text { (r) جدول (r) }
$$

اعتدالية أفراد عينة البحث في المتغيرات قيد البحث

\begin{tabular}{|c|c|c|c|c|c|}
\hline الالتو اء & الانحر اف المعياري & الوسيط & الحتوسط الحسى & وحدة القياس & الدلالات الإحص \\
\hline$\because \cdot 17-$ & r.01 & $r_{1} \ldots$ & $r \cdot .9 \wedge$ & درجة & الذكاء اللغوى / الثفهى \\
\hline$\because \vee \wedge \cdot-$ & $\leqslant . \leqslant 1$ & $r \leq .$. & rY.Ao & درجة & الذكاء الرياضى / المنطقى \\
\hline$\because \cdot 7-$ & $\leqslant .0$ & $r_{1} \ldots$ & $r \cdot .91$ & د & الذكاء المكانى / البصرى \\
\hline $.0 \leqslant-$ & r. & ro... & $r \varepsilon . r$ & درجة & الذكاء الحركى / الجسمى \\
\hline$. .17-$ & $0 . \leqslant 0$ & $r \cdot \ldots$ & 19.8. & د & الذكاء الموسيقى / الإيقاعى \\
\hline .11 & r. & $r \varepsilon \ldots$ & YE.YY & د & الذكاء الإجتماعى/ بين الأشخاص \\
\hline$\because 0-$ & 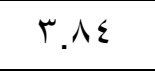 & $r \varepsilon \ldots$ & מצ. & د & الذكاء الثخصى / الذاتى \\
\hline$. \varepsilon V-$ & 19.19 & $17 \cdot \ldots$ & 107.91 & د & مجمو ع الذكاءات \\
\hline r. r & r. & 1vo. & IVR.T & سم & الطول \\
\hline $.9 V$ & 1.9 & VY.O & RT.IT & كجم & 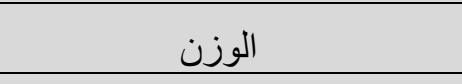 \\
\hline.$V V$ &.$r$ & 0.0 & 0.01 & سنة & العمر التدريبى \\
\hline
\end{tabular}

يتضح من جدول (Y) أن البيانات الخاصة بعينة البحث الكلية معتدلة وغير مشتتة وتتسم

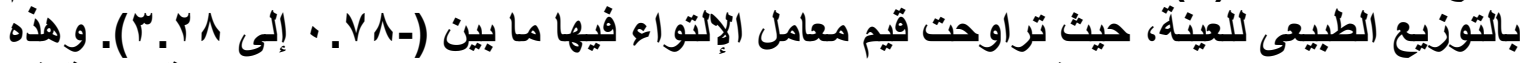

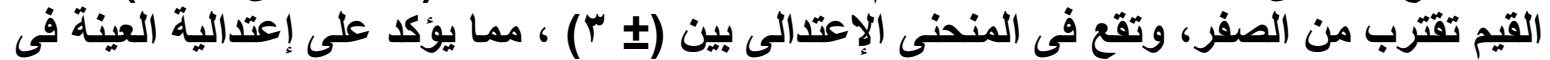

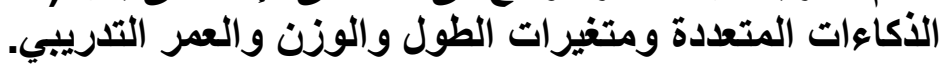




\section{جدول (r)}

حساب معامل صدق التمييز للأكاعات المتعددة والاختبارات المهارية لعينة البحث الاستطلاعية

\begin{tabular}{|c|c|c|c|c|c|c|}
\hline \multirow[t]{2}{*}{ T-test } & \multirow{2}{*}{ المتوسطين } & \multicolumn{2}{|c|}{ مجمو عة لاعبي كرة القدم تحنة } & \multicolumn{2}{|c|}{ مجموعة لاعبي كرة القدم } & \multirow[t]{2}{*}{ المتغير ات } \\
\hline & & $\varepsilon \pm$ & س & $\varepsilon \pm$ & س & \\
\hline$* \varepsilon \ldots$ & $\varepsilon$. & 1.71 & $1 V . \varepsilon$ & r.o. & r). & الذكاء اللغوى / الشفهى \\
\hline$* \varepsilon . Y \wedge$ & $\varepsilon .77$ & $1 . \wedge V$ & 18.77 & r.79 & 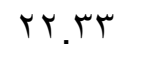 & الذكاء الرياضى / المنطقى \\
\hline$*$ *V $V \varepsilon$ & $r .57$ & Y. $\leqslant 1$ & 11.77 & $r .99$ & r & الذكاء المكانى / البصرى \\
\hline$* \leqslant . Y \leqslant$ & 0.11 & r. & 11. & r. r. & דצr. & الذكاء الحركح \\
\hline *t.r & 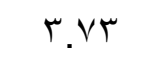 & r.00 & 19.17 & r. VO & r.... & الذكاء الموسيقى / الإيقاعى \\
\hline$* \varepsilon .97$ & $V .7$ & $r . q 4$ & $1 V . \wedge$ & r.9V & $r \varepsilon . \wedge T$ & الذكاء الإجتماعى/ بين الأشخاص \\
\hline$*$ * $\leq q$ & $\varepsilon .77$ & $r .7 \leq$ & $r \cdot .1 r$ & r tr & $r \leq . \wedge$. & 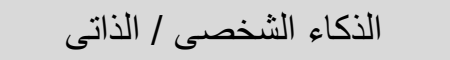 \\
\hline$* Y .00$ & 1.04 & 1.7. & $1 \varepsilon .7$ & r. & 10.7 & الجرى المتعرج \\
\hline *r. & $\leqslant .0$ & $\leqslant . \leqslant 7$ & r r & דוץ. & r & ركل الكرة لابعد مسافة \\
\hline *T.0. & سب. & r. & ro. 77 & $\varepsilon .1 \varepsilon$ & r^... & السيطرة على الكرة بباطن القدم \\
\hline *Y.0. & 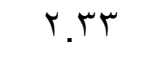 & $1 . \wedge \wedge$ & 7.11 & r.AV & $\Lambda . \leqslant 7$ & دقة التمرير بباطن القدم \\
\hline$* r . V V$ & 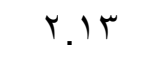 & r. 9 & IV.IT & $0 . r$ & 19.17 & رمية التماس لأبعد مسافة \\
\hline *ז.^. & 1.97 & 1.14 & V.7. & $1 . \wedge 9$ & 9.07 & ضرب الكرة بالر أس لأبعد مسافة \\
\hline
\end{tabular}

$(Y . V \cdot)=\cdot .0$. معنوى عند مستوى*

يتضح من جدول رقم (ب) وجود فروق دالة إحصائيا بين المجموعتين المميزة والغير مميزة، مما

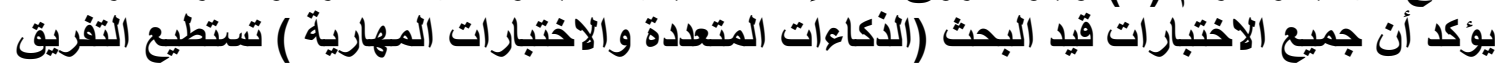
بين المجموعتين المميزة والغير مميزة. 
جدول (؛)

حساب معامل الثبات لقائمة الأكاعات المتعددة والاختبارات المهارية

لعينة البحث الاستطلاعية

\begin{tabular}{|c|c|c|c|c|c|}
\hline \multirow{2}{*}{ قيمة (ر) } & \multicolumn{2}{|c|}{ 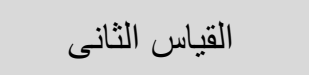 } & \multicolumn{2}{|c|}{ القياس الأول } & \multirow{2}{*}{ المتعددة } \\
\hline & $\varepsilon \pm$ & س س & $\varepsilon \pm$ & 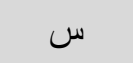 & \\
\hline$* . \wedge V$ & 1.91 & $r \cdot . q r$ & r.o. & rI. $\varepsilon$. & الذكاء اللغوى / الشفهى \\
\hline$*$. vo & 1.91 & Y). .74 & r.79 & שT.ru & الذكاء الرياضى / المنطقى \\
\hline$* . . \wedge V$ & r.or & Y). $\leqslant T$ & r.99 & rt.it & الذكاء المكانى / البصرى \\
\hline *..人 & r.r人 & rr.or & $r . \varepsilon r$ & Tr.ru & الذكاء الحركى / الجسمى \\
\hline$* .9$ & r.jr & rr.or & r.vo & rז... & الذكاء الموسيقى / الإيقاعى \\
\hline$* . .97$ & $r .91$ & $r \leq .7 T$ & r. $9 V$ & $r \leqslant . \wedge T$ & الألكاء الإجتماصى/ بين \\
\hline$* .9 r$ & $r .91$ & $r \leq .77$ & r.it & $r \leq . \wedge$. & الذكاء الثخصى / الذاتى \\
\hline$* . \wedge 1$ & r.IV & 10.r & r.rq & 10.7 & الجرى المتعرج \\
\hline$* .19$ & r.q. & rq. r. & ร. & $r \cdot .1 r$ & ركل الكرة لابعد مسافة \\
\hline$* .90$ & $\varepsilon .1$ & $r v . \varepsilon$ & $\varepsilon .1 \leq$ & r^... & السيطرة على الكرة بباطن القدم \\
\hline$* . \wedge 7$ & r.) & $\vee . \wedge T$ & r.Av & $\wedge . \leqslant 7$ & دقة التمرير بباطن القدم \\
\hline$* .9$ & $\varepsilon . r$ & $1 \wedge . r$ & $0 . r$ & 19.17 & رمية التماس لأبعد مسافة \\
\hline$* .94$ & $1.7 \varepsilon$ & 9.r. & 1.19 & 9.07 & ضرب الكرة بالر أس لأبعد \\
\hline
\end{tabular}

يتضح من جدول رقم (ع ) وجود فروق دالة إحصائيا بين القياس الأول والقياس الثانى، مما يؤكد

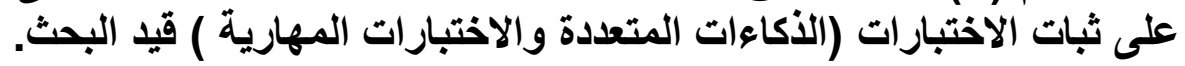

الأدوات والأجهزة المستخدمة:

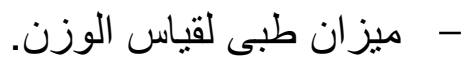

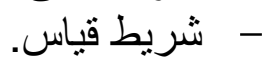

استخدم الباحث فى جمع البينات المتعلقة بالبحث على مجموعة من الأدوات التالية: 
• مسح المر اجع و الأبحاث و الدوريات العلمية المتخصصة فى موضوع البحث، و الثبكة

$$
\text { العالمية للمعلومات internet }
$$

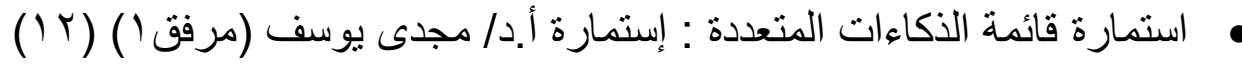

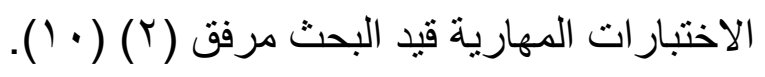

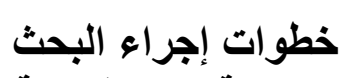

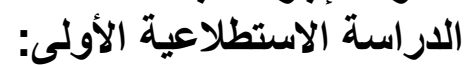

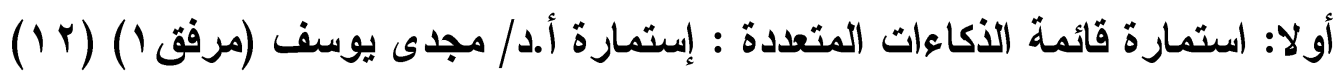

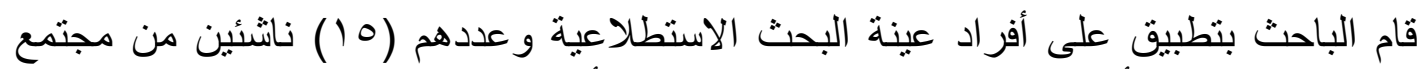

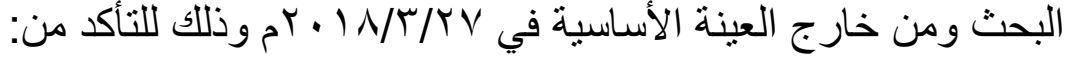

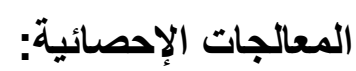

تم ايجاد المعالجات الاحصائية باستخدام برنامج 20 SPSS version فيما يلى :

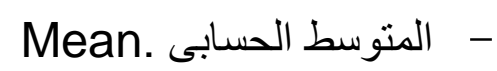

- الانحر اف المعيارى Stander Deviation -

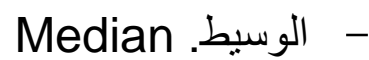

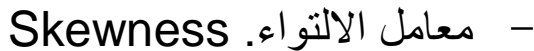

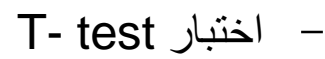

- النسبة المئوية مercentage -

- معامل الإرتباط لبيرسون -

one - way - anova تحليل التباين الإنباطن -

- اختبار اقل فرق معنوى ( LSD ) - 


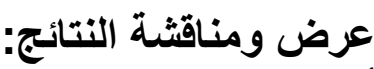

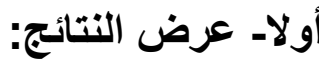

(0) جدول

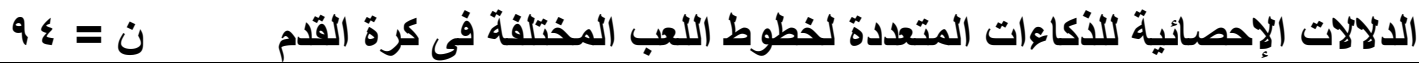

\begin{tabular}{|c|c|c|c|c|c|c|c|}
\hline الالتواء & الانحر افياري & الوسيط & المتيط الحسبى & عدد & مراكز & القياس & (i) \\
\hline$. r \varepsilon-$ & $\varepsilon \ldots q$ & r..e. & ri.1V & ir & حر اس المرمى & \multirow{4}{*}{ درجة } & \multirow{4}{*}{ الأكاء اللغوى / الشفهى } \\
\hline $.7 \leqslant-$ & $r .94$ & M... & $r . .01$ & rv & لاعبي خط الدفاع & & \\
\hline$. .+r-$ & $r . . r$ & rr... & Y1.94 & rr & لاعبي خط الوسط & & \\
\hline$. . r r-$ & T.YT & r.... & $r . . T \varepsilon$ & rr & لاعبي خط الهجوم & & \\
\hline. .11 & $\varepsilon . \varepsilon T$ & r... & YI.IV & ir & حراس المرمى & \multirow{4}{*}{ درجة } & \multirow{4}{*}{ الأكاء الرياضى / المنطقى } \\
\hline$\cdot . \leqslant 9-$ & $\varepsilon .74$ & rr... & YY.YE & $r v$ & لاعبي خط الافاع & & \\
\hline$. A r-$ & r.V^ & ro... & rr.9T & r & لاعبي خط الوسط & & \\
\hline$. .0 \mathrm{~V}-$ & $\varepsilon . \varepsilon V$ & $r \leq .0$. & YT.TE & rr & لاعبي خط الهجوم & & \\
\hline$. .74-$ & 0.71 & r.... & 19.20 & ir & حراس المرمى & \multirow{4}{*}{ درجة } & \multirow{4}{*}{ الأكاء المكانى / البصرى } \\
\hline$\because v \varepsilon$ & r.9r & $19 .$. & $19.9 \mathrm{~V}$ & $r v$ & لاعبي خط الدفاع & & \\
\hline $1 .+\varepsilon-$ & $r . v r$ & rr... & ri.v. & rr & لاعبي خط الوسط & & \\
\hline$. . r 9-$ & D.rT & rr... & rr.tr & $r r$ & لاعبي خط الهجوم & & \\
\hline I.rY - & $\varepsilon \ldots \wedge$ & $r\{\ldots$ & rr.rr & ir & حراس المرمى & \multirow{4}{*}{ درجة } & \multirow{4}{*}{ الأكاء الحركى / الجسمى } \\
\hline .99 & r.Yr & ro... & $r \varepsilon \ldots$ & rv & لاعبي خط الدفاع & & \\
\hline$\therefore v \cdot-$ & $r . v$. & r... & ro.1r & rr & لاعبي خط الوسط & & \\
\hline $.19-$ & r.Or & ro.o. & ro.ru & rr & لاعبي خط الهجوم & & \\
\hline $1.19-$ & $7 . \leqslant 0$ & r..e. & $19 . \ldots$ & Ir & حراس المرمى & \multirow{4}{*}{ درجة } & \multirow{4}{*}{ الأكاء الموسيقى / الإيقاعى } \\
\hline$\therefore \leqslant 0-$ & 0.01 & r... & $r . .17$ & rv & لاعبي خط الدفاع & & \\
\hline . .Or & $0.1 r$ & $19 .$. & 19.91 & rr & لاعبي خط الوسط & & \\
\hline. .71 & $0 . Y A$ & $11 .$. & $19 . .9$ & rr & لاعبي خط الهجوم & & \\
\hline .04 & r.74 & $r \leq .0$. & $r \varepsilon \ldots$ & ir & حراس المرمى & \multirow{4}{*}{ درجة } & \multirow{4}{*}{ الذكاء الإجتماعى/ بين الأشخاص } \\
\hline$\ldots+1-$ & $\varepsilon .07$ & $r \leq \ldots$ & rr. $9 \mathrm{~V}$ & $r v$ & لاعبي خط الدفاع & & \\
\hline .10 & r.YY & $r \leq \ldots$ & $r \varepsilon . I V$ & rr & لاعبي خط الوسط & & \\
\hline .10 & r.AV & $r \varepsilon \ldots$ & $r \varepsilon . \wedge r$ & rr & لاعبي خط الهجوم & & \\
\hline $1 . .9-$ & T.\& \& & $r \leq \ldots$ & YY.VO & ir & حراس المرمى & \multirow{4}{*}{ درجة } & \multirow{4}{*}{ الأكاء الشخصى / الأتى } \\
\hline$\cdot . \wedge \wedge-$ & $\varepsilon \ldots$ & $r \leqslant \ldots$ & YY.AI & $r v$ & لاعبي خط الافاع & & \\
\hline $1.19-$ & r.Vr & rv... & ro.0r & $r r$ & لاعبي خط الوسط & & \\
\hline $1.19-$ & r.11 & หч... & $Y \varepsilon . V V$ & rr & لاعبي خط الهجوم & & \\
\hline
\end{tabular}

يتضح من جدول (0) أن البيانات الخاصة بعينة البحث الكلية معتدلة وغير مشتتة وتتسم

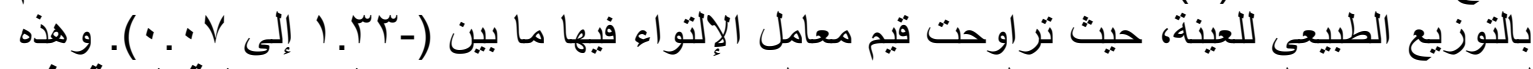

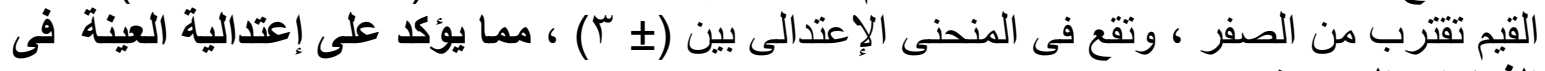

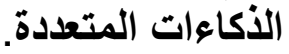




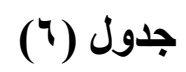

دلالة الفروق بين مراكز اللعب فى كرة القدم فى الأكاءات المتعددة قيد البحث ن = ؟

\begin{tabular}{|c|c|c|c|c|c|c|}
\hline مستوى الدلالة & قفيمة & متوسط المربعات & الحرية & المربعات & مصدر التباين & ات \\
\hline \multirow{3}{*}{ 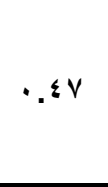 } & \multirow{3}{*}{$\cdot \wedge \bullet$} & $11 .$. & $r$ & rr... & بين المجموعات & \multirow{3}{*}{ الأكاء اللغوى / الشفهى } \\
\hline & & $\mid Y . \wedge \wedge$ & 9. & 1101.97 & داخل المجموعات & \\
\hline & & & $q 4$ & 1191.97 & المجموع & \\
\hline \multirow{3}{*}{$\cdot r \cdot$} & \multirow{3}{*}{1.07} & r৭.1. & $r$ & 19. & بين المجموعات & \multirow{3}{*}{ الأكاء الرياضى / المنطقى } \\
\hline & & $19.1 \%$ & 9. & IVY..Or & داخل المجموعات & \\
\hline & & & $q 4$ & 11.9 .91 & المجموع & \\
\hline \multirow{3}{*}{.10} & \multirow{3}{*}{1.89} & $r 0 . \leqslant \Lambda$ & $r$ & $1 \cdot 7 . \leqslant 0$ & بين المجموعات & \multirow{3}{*}{ الأكاء المكانى / البصرى } \\
\hline & & $19 . \vee 9$ & 9. & $I \vee \wedge \cdot . \wedge V$ & داخل المجموعات & \\
\hline & & & $q 4$ & 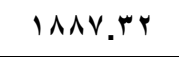 & المجموع & \\
\hline \multirow{3}{*}{$\because \cdot 0$} & \multirow{3}{*}{ *r.Vr } & rq.90 & $r$ & $\wedge 9 . \wedge 0$ & بين المجموعات & \multirow{3}{*}{ الأكاء الحركى / الجسمى } \\
\hline & & $11 .$. & 9. & $99 \cdot . r v$ & داخل المجموعات & \\
\hline & & & 94 & $1 \cdot \Lambda \cdot . r 1$ & المجموع & \\
\hline \multirow{3}{*}{$\cdot . \wedge 4$} & \multirow{3}{*}{$\cdot r o$} & V.74 & $r$ & YY.q9 & بين المجموعات & \multirow{3}{*}{ الأكاء الموسيقى / الإيقاعى } \\
\hline & & $r \cdot . \leqslant r$ & 9. & rVHA.TV & داخل المجموعات & \\
\hline & & & 94 & rvq1.79 & المجموع & \\
\hline \multirow{3}{*}{$\cdot \wedge \bullet$} & \multirow{3}{*}{. .47} & r.09 & $r$ & $1 \cdot .87$ & بين المجموعات & \multirow{3}{*}{ الأكاء الإجتماصى / بين } \\
\hline & & $|r . v|$ & 9. & Irrr.00 & داخل المجموعات & \\
\hline & & & 94 & $|r \leq \varepsilon . r|$ & المجموع & \\
\hline \multirow{3}{*}{$\because \cdot r$} & \multirow{3}{*}{ Ar.rt } & $\leq 0.70$ & $r$ & 114.90 & بين المجموعات & \multirow{3}{*}{ الأكاء الشخصى / الذاتى } \\
\hline & & Ir.vr & 9. & Irro.or & داخل المجموعات & \\
\hline & & & 94 & ITVY.\&A & المجموع & \\
\hline \multirow{3}{*}{.17} & \multirow{3}{*}{$1 . \vee \wedge$} & $7 r q .49$ & $r$ & $191 \mathrm{V.AV}$ & بين المجموعات & \multirow{3}{*}{ مجموع الأكاءات } \\
\hline & & roq.11 & 9. & rrmr... & داخل المجموعات & \\
\hline & & & 94 & $r \varepsilon r r V . q 7$ & المجموع & \\
\hline
\end{tabular}

$(Y . Y \cdot)=\cdot .0$. معنوى عند مستوى*

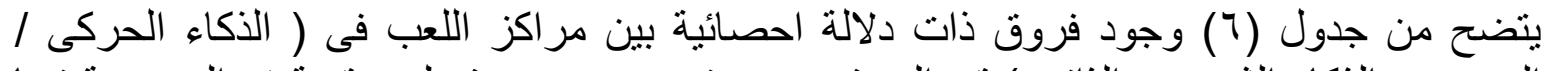

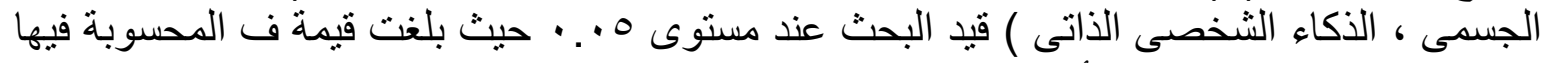

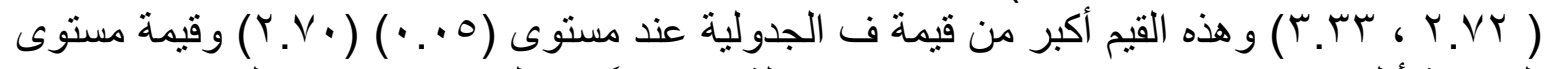

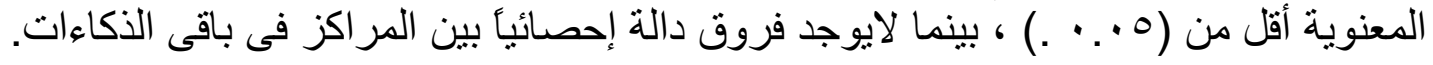


جدول (v)

اختبار L.S.D عند مستوى ه • . . لتحديد معنوية واتجاه الفروق فى الأكاء الحركى / الجسمى

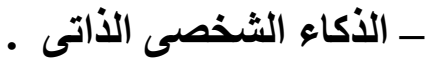

\begin{tabular}{|c|c|c|c|c|}
\hline مستوى & المترق بين & الفئة الفر عية & الفئة الرئيسية & الأكاءات \\
\hline. .14 & $1.7 \mathrm{~V}-$ & لاعبى خط الدفاع & \multirow{3}{*}{ حراس المرمى } & \multirow{12}{*}{ الأكاء الحركى| } \\
\hline$\cdots r$ & $*$ *.^.- & لاعبى خط الوسط & & \\
\hline$\ldots 1$ & $*$ *. r r- & لاعبى خط الهجوم & & \\
\hline. .14 & $1.7 \mathrm{~V}$ & حراس المرمى & \multirow{3}{*}{ لاعبى خط الافاع } & \\
\hline.$r$. & $1.1 \mathrm{r-}$ & لاعبى خط الوسط & & \\
\hline. $.1 r$ & $1 . r 9-$ & لاعبى خط الهجوم & & \\
\hline$\ldots r$ & *r.^. & حراس المرمى & \multirow{3}{*}{ لاعبى خط الوسط } & \\
\hline.$r$ & $1.1 \mathrm{r}$ & لاعبى خط الدفاع & & \\
\hline..$\wedge 1$ & $. r r-$ & لاعبى خط الهجوم & & \\
\hline$\ldots 1$ & $* r . \cdot r$ & حراس المرمى & \multirow{3}{*}{ لاعبى خط الهجوم } & \\
\hline. .14 & $1 . \mathrm{Ty}$ & لاعبى خط الدفاع & & \\
\hline. .11 & . & لاعبى خط الوسط & & \\
\hline. .97 & $\cdots 7-$ & لاعبى خط الدفاع & \multirow{3}{*}{ حراس المرمى } & \multirow{12}{*}{ الأكاء الشخصى } \\
\hline$\ldots \varepsilon$ & $*$ *.VV- & لاعبى خط الوسط & & \\
\hline. $.1 r$ & $r . \cdot r-$ & لاعبى خط الهجوم & & \\
\hline .997 & $\ldots .7$ & حراس المرمى & \multirow{3}{*}{ لاعبى خط الدفاع } & \\
\hline$\ldots+1$ & *Y.VI- & لاعبى خط الوسط & & \\
\hline$\ldots 0$ & $1.97-$ & لاعبى خط الهجوم & & \\
\hline$\cdots \varepsilon$ & *r.vV & حراس المرمى & \multirow{3}{*}{ لاعبى خط الوسط } & \\
\hline$\ldots 1$ & $* r . v 1$ & لاعبى خط الدفاع & & \\
\hline .0 &.$v 0$ & لاعبى خط الهجوم & & \\
\hline. .14 & $r . r$ & حراس المرمى & \multirow{3}{*}{ لاعبى خط الهجوم } & \\
\hline$\ldots 0$ & 1.97 & لاعبى خط الدفاع & & \\
\hline .0. & $. v 0-$ & لاعبى خط الوسط & & \\
\hline
\end{tabular}

يتضح من جدول (V) الخاص باختبار L.S.D عند مستوى ه . . . لتحديد معنوية واتجاه الفروق فى في

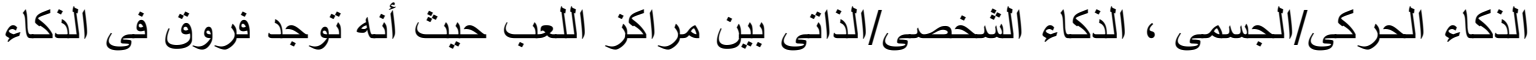

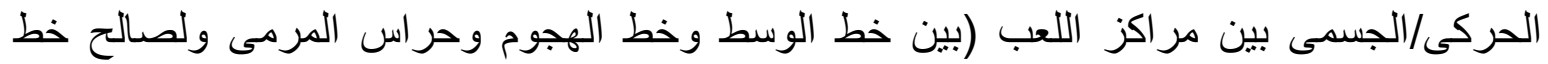

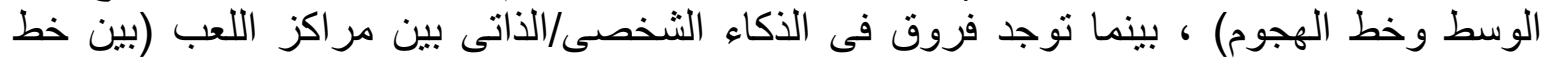

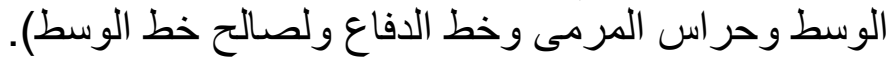




\section{جدول (^)}

دلالة الفروق بين مراكز اللعب فى كرة القدم فى الاختبارات المهارية قيد البحث ن = ع

\begin{tabular}{|c|c|c|c|c|c|c|}
\hline الالائة & قفيمة & متوسط المربعات & الحرية & المربعات & مصدر التباين & \\
\hline \multirow{3}{*}{.01} & \multirow{3}{*}{$r . \varepsilon \varepsilon$} & 9.7 & $r$ & $r V . \& \Lambda$ & بين المجموعات & \multirow{3}{*}{ الجري المتعرج / ث } \\
\hline & & $r . V \leq$ & 17 & $\bullet ৭ . \wedge V$ & داخل المجموعات & \\
\hline & & & 19 & AV.ro & المجموع & \\
\hline \multirow{3}{*}{$\cdot . \leqslant 9$} & \multirow{3}{*}{$\cdot . \wedge r$} & $10.9 V$ & $r$ & $\leqslant V .9 Y$ & بين المجموعات & \multirow{3}{*}{ ركل الكرة لأبعد مسافة } \\
\hline & & 19.59 & 17 & $r \cdot \Lambda . v 1$ & داخل المجموعات & \\
\hline & & & 19 & ro9.7r & المجموع & \\
\hline \multirow{3}{*}{..$\leqslant 7$} & \multirow{3}{*}{$\cdot . \wedge 9$} & 10.rV & $r$ & $\leqslant 0 . \wedge r$ & بين المجموعات & \multirow{3}{*}{ السبطرة على الكرة بباطن } \\
\hline & & IV.IT & 17 & $r v \varepsilon .17$ & داخل المجموعات & \\
\hline & & & 19 & r.... & المجموع & \\
\hline \multirow{3}{*}{$\because+11$} & \multirow{3}{*}{$\varepsilon . r q$} & YY.90 & $r$ & $\checkmark \wedge . \wedge 0$ & بين المجموعات & \multirow{3}{*}{ دقة التمرير بباطن القدم } \\
\hline & & 9.99 & 17 & 109.90 & داخل المجموعات & \\
\hline & & & 19 & rイ^.^. & المجموع & \\
\hline \multirow{3}{*}{$\because .99$} & \multirow{3}{*}{$\cdot . \wedge r$} & 19.0 & $r$ & 0.10 & بين المجموعات & \multirow{3}{*}{ رميه تماس لأبعد مسافة } \\
\hline & & rY.As & 17 & $m \div 0 . \leqslant 1$ & داخل المجموعات & \\
\hline & & & 19 & $\varepsilon r$ \&.7r & المجموع & \\
\hline \multirow{3}{*}{.09} & \multirow{3}{*}{$.7 \varepsilon$} & Y. $\$ 4$ & $r$ & V.\&. & بين المجموعات & \multirow{3}{*}{ ضرب الكرة بالر أس لأبعد } \\
\hline & & r.^. & 17 & $7 \cdot \Lambda \mu$ & داخل المجموعات & \\
\hline & & & 19 & $\checkmark \Lambda . Y$ & المجموع & \\
\hline
\end{tabular}

$$
(Y . V \cdot)=\cdot .0 \text {. معنوى عند مستوى* }
$$

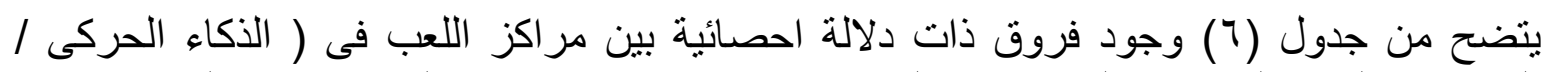

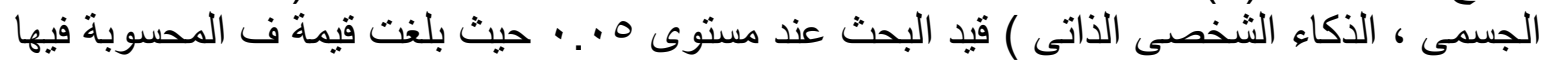

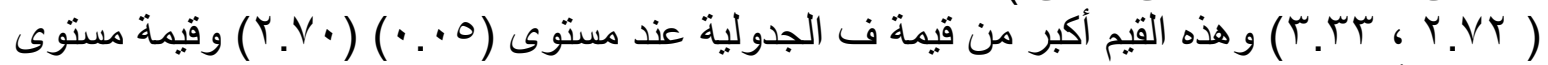

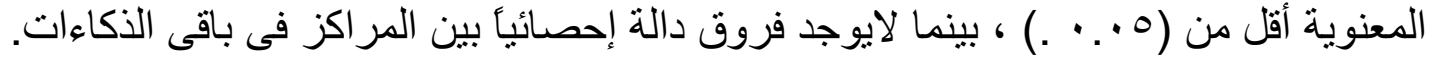


جدول (9)

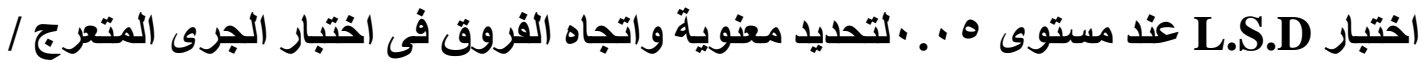

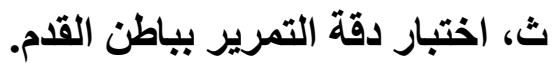

\begin{tabular}{|c|c|c|c|c|}
\hline مستوى & الفرق بين & القئة الفرعية & الفئة الرئيسية & الأكاءات \\
\hline$\cdots 4$ & r.A.- & لاعبى خط الدفاع & \multirow{3}{*}{ حراس المرمى } & \multirow{12}{*}{ الجري المتعرج / ث } \\
\hline.$v V$ & $. r v-$ & لاعبى خط الوسط & & \\
\hline..$\wedge \wedge$ &. .41 & لاعبى خط الهجوم & & \\
\hline$\cdots 4$ & r.^. & حراس المرمى & \multirow{3}{*}{ لاعبى خط الدفاع } & \\
\hline$\cdots \varepsilon \varepsilon$ & $r . \leqslant r$ & لاعبى خط الوسط & & \\
\hline$\ldots r$ & $r . .1$ & لاعبى خط الهجوم & & \\
\hline.$v V$ &..$r v$ & حراس المرمى & \multirow{3}{*}{ لاعبى خط الوسط } & \\
\hline..$\leqslant \mu$ & $r . \Sigma r-$ & لاعبى خط الدفاع & & \\
\hline $.7 r$ &. .09 & لاعبى خط الهجوم & & \\
\hline..$\wedge \wedge$ & $. . M 1-$ & حراس المرمى & \multirow{3}{*}{ لاعبى خط الهجوم } & \\
\hline$\ldots r$ & r...1- & لاعبى خط الدفاع & & \\
\hline $.7 r$ & $.09-$ & لاعبى خط الوسط & & \\
\hline$\cdots \cdot 7$ & $\leq .7$. & لاعبى خط الدفاع & \multirow{3}{*}{ حراس المرمى } & \multirow{12}{*}{ دقة التمرير بباطن } \\
\hline. .11 & $\ldots 0$ & لاعبى خط الوسط & & \\
\hline .91 &. ro & لاعبى خط الهجوم & & \\
\hline$\cdots \cdot 7$ & $\varepsilon .7 .-$ & حراس المرمى & \multirow{3}{*}{ لاعبى خط الدفاع } & \\
\hline$\ldots r$ & $\varepsilon .1 .-$ & لاعبى خط الوسط & & \\
\hline$\ldots 0$ & $\varepsilon . r o-$ & لاعبى خط الهجوم & & \\
\hline. .11 & $.0 .-$ & حراس المرمى & \multirow{3}{*}{ لاعبى خط الوسط } & \\
\hline$\ldots r$ & $\varepsilon .1$. & لاعبى خط الدفاع & & \\
\hline. .19 &. ro- & لاعبى خط الهجوم & & \\
\hline .991 & $. r O-$ & حراس المرمى & \multirow{3}{*}{ لاعبى خط الهجوم } & \\
\hline$\ldots 0$ & \&.Mo & لاعبى خط الدفاع & & \\
\hline. .19 & . r & لاعبى خط الوسط & & \\
\hline
\end{tabular}

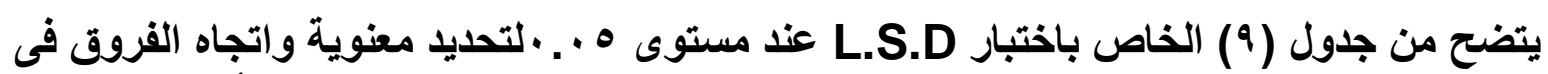

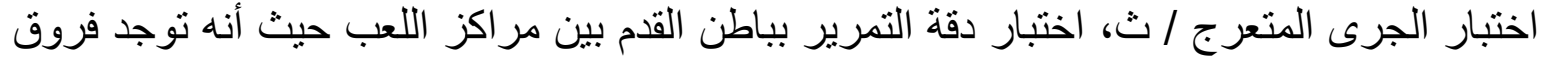

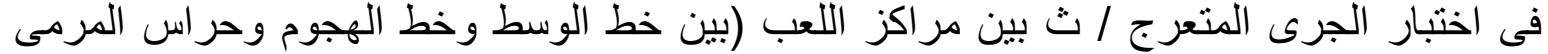

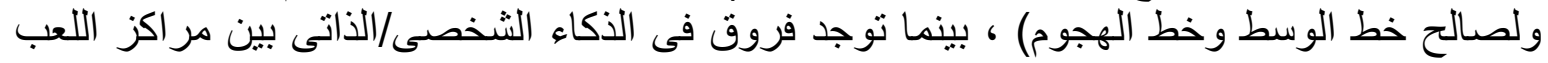
(بين خط الوسط وحر اس المرمى وخط الدفاع ولصالح خط الوسط). 
$9 \varepsilon=\dot{0}$

جدول ( • ( ) يوضح مصفوفة الارتباط بين الأكاءات المتعددة والإختبارات المهارية للاعبى كرة القدم عينة البحث.

\begin{tabular}{|c|c|c|c|c|c|c|c|c|c|c|c|c|c|c|}
\hline بالكرب الكرة & لأبعد مسافة التماس & بباطن التمرير & بباطن القامة & لابعد مسافة & الجترج & الذكاءات & الثخصى / الذاتى & الإجتماعى / الأثاء & الموسيقى / الإيقاء & الجسمى / الأكاء & البكانى I النكاء & الرياضقى ا الأكاء & اللثفوى / الذكاء & مصفوفة الارتباط \\
\hline & & & & & & & & & & & & & & الذكاء اللغوى / الثنفهى \\
\hline & & & & & & & & & & & & & *. H R & الذكاء الرياضى / المنطقى \\
\hline & & & & & & & & & & & & $* ., r \leqslant r$ &. $.1 \wedge r$ & الذكاء المكانى / البصرى \\
\hline & & & & & & & & & & & $* ., q_{\text {. }}$ & .094 & $* . .0 \leq r$ & الذكاء الحركى / الجسمى \\
\hline & & & & & & & & & & $* . . \leqslant 74$ & *. rqu & $* . . \leqslant 4$ & $* . . \leqslant 9 \leqslant$ & الذكاء الموسيقى / الإيقاعى \\
\hline & & & & & & & & & $* .0 \leq V$ & $* ., V \vee r$ & $* . .0 V Y$ & *. r. & $* ., r \Delta 1$ & الذكاء الإجتماعى/ بين الأنخاص \\
\hline & & & & & & & &. $.1 T r$ & $* . .0 \wedge r$ &. .19 &. .170 & *.. ז. &. $.0 r$ & الذكاء الثخصى / الذاتى \\
\hline & & & & & & & $*_{.} . \leqslant 0 \leqslant$ & $* . . \wedge .7$ & $* . \vee \vee$ & $* . \vee \vee q$. & $* . .7 . r$ & $* . .7 \wedge \varepsilon$ & $* . .09 \leq$ & مجموع الذكاءات \\
\hline & & & & & & $. .11 \mathrm{~V}-$ &. $.9 V$. & .189 & $* ., Y 01=$ & .991 & _ & $* . .\{Y 1=$ & $. .9 \leq-$ & الجرى المتعرج \\
\hline & & & & & $* .$, r & $.1 \wedge v-$ & .1 r & $\cdot . \bullet r_{-}$ & $\because \leqslant 9$ & $* ., r \cdot \Lambda-$ & *.,r $r \leqslant \leq$ & . . rq. & $\cdot . \varepsilon_{-}$ & ركل الكرة لابعد مسافة \\
\hline & & & & *..OY & $* .$, *०1. & $* \cdot r \cdot v=$ &..$V r$ & .191. &. .190. & $*$. * $\wedge 0_{-}$ & *. . 99 &. $.9 \cdot$ & $*, r \wedge \wedge$ & السيطرة على الكرة بباطن القدم \\
\hline & & & $* ., r \mu v$ & $* . . \ldots$ & $* . .00 V=$ & $\cdot 1 \ldots$ &.,$Y \wedge$. & .119 &. $.7 \varepsilon$ & $\because v$. & *. . \& Y O & $. \cdot \leq r$ &. .18. & دقة التمرير بياطن القدم \\
\hline & & *. & *. . & *. . & $*, . r \leq 7-$ &. $.19 r$ &. .01 & $* ., r q r$ &. $.7 V$ & $* ., r . q$ &.$\cdots 1$ &. .517 & $. .9 \cdot-$ & رمية التماس لأبعد مسافة \\
\hline & $* ., Y \wedge I$ &. $.0 \Lambda_{-}$ & $* . .4 q q$ & *. & $. .1 \leq$ & $. .101-$ & $. .0 \leqslant$ &. .11. & $* ., r \leqslant \theta_{-}$ & *. r. & *.,rr. &. .171 & $* ., r v \leq-$ & ضرب الكرة بالر أس لأبعد مسافة \\
\hline
\end{tabular}

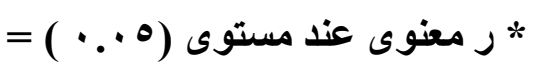

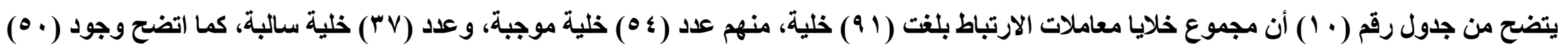
خلية دالة. 


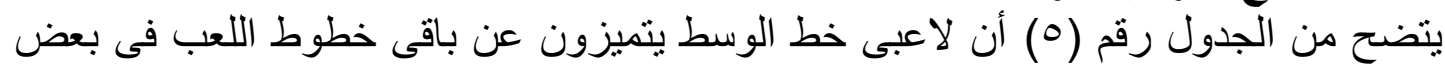

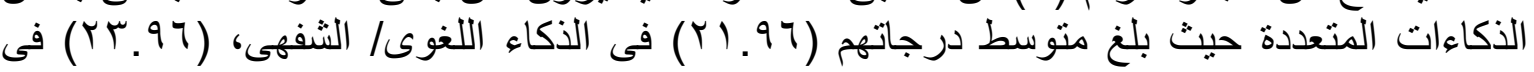

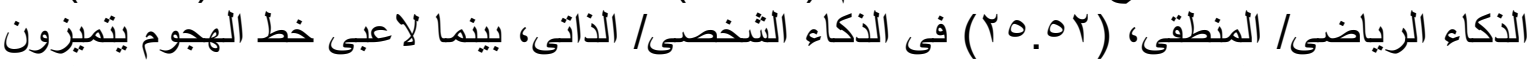

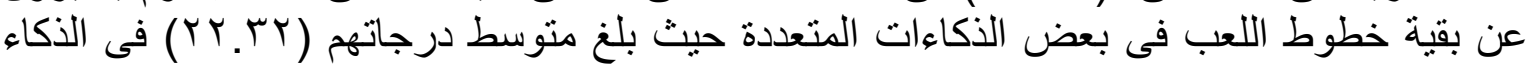

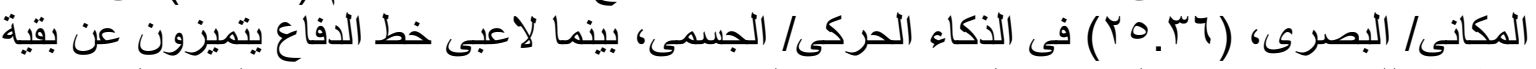

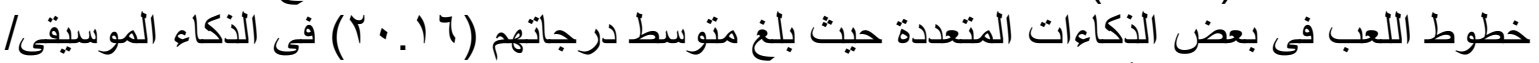

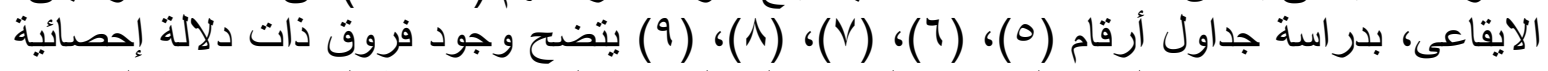

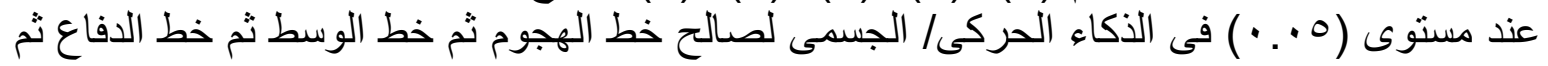

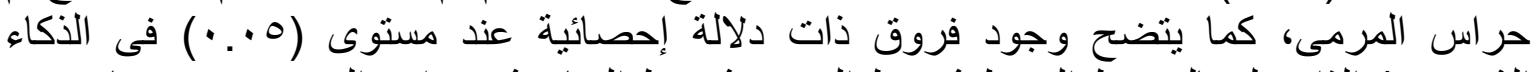

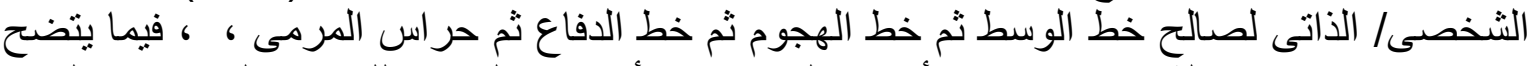

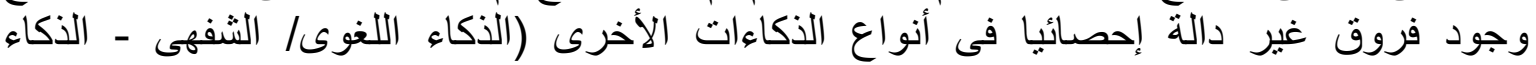
الرياضى/ المنطقى - الذكاء المكانى/ البصرى - الذكاء الموسيقى/ الإيقاعى - الذكاء الإجتماعى/ الأهاء بين

(الأشخاص ) الرياصى )

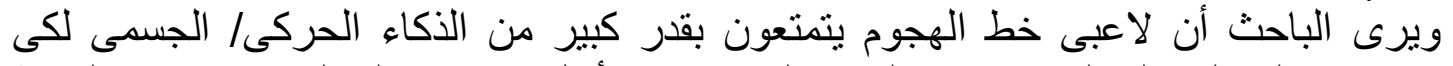

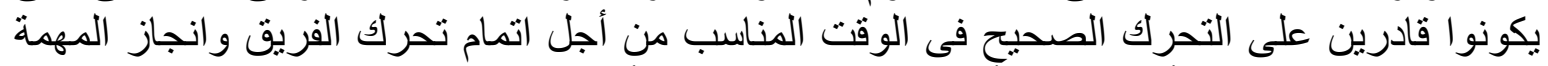

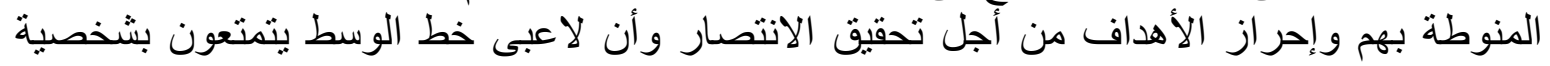
قوية تعطيه الفرصة لرؤية المللعب وتقدير الفراغ واغ والمكان مما يمكنه من حل المشكلات الهجو التهية و الافاعية التى يو اجهها بنجاح.

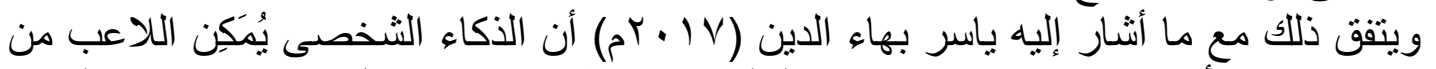

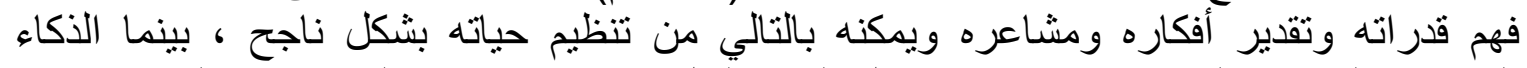

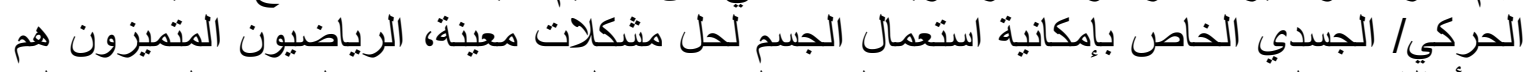

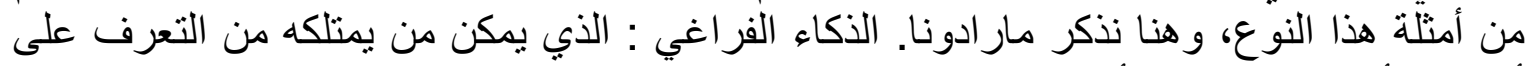

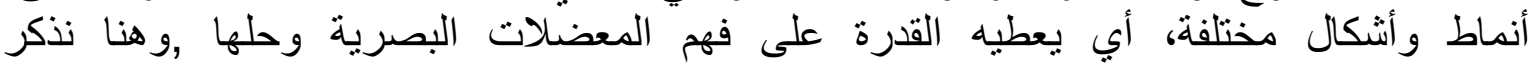
بيكاسو(0) (10)

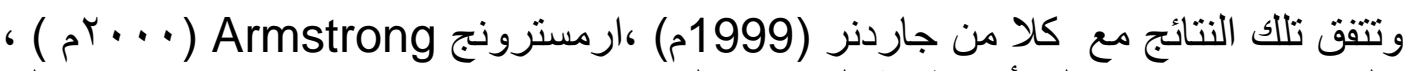

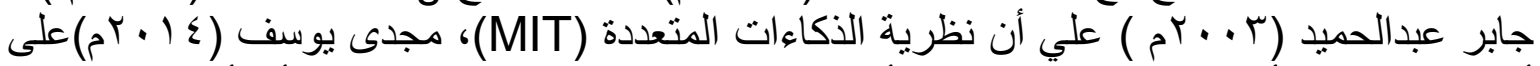

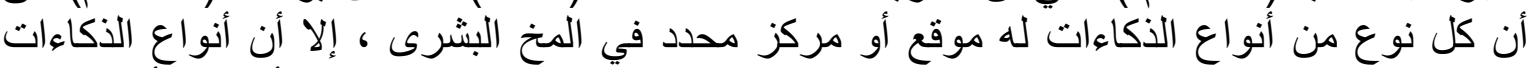

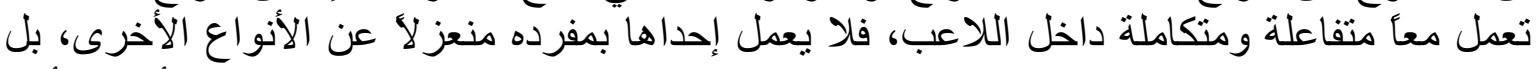

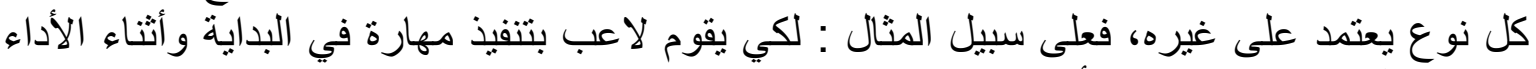

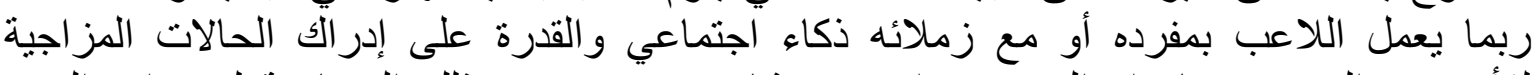

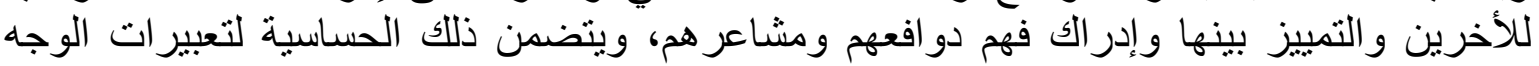

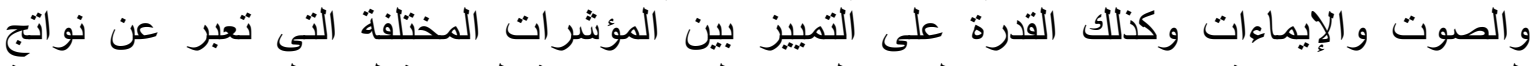

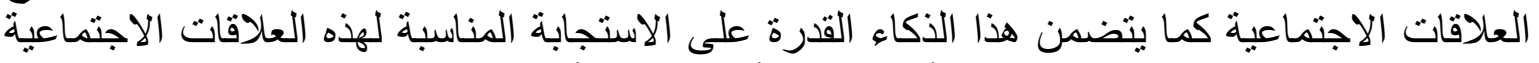

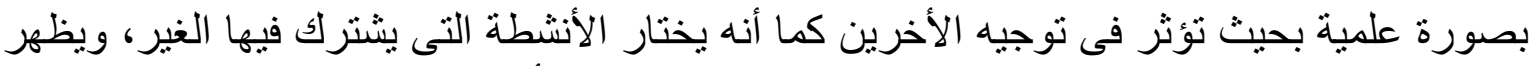

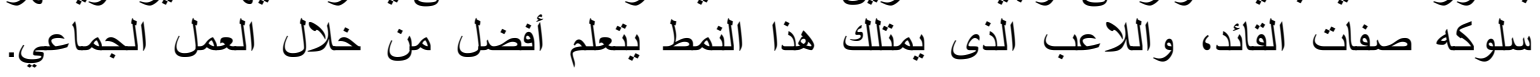

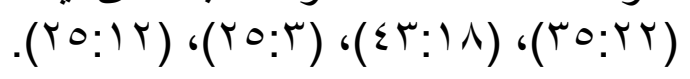

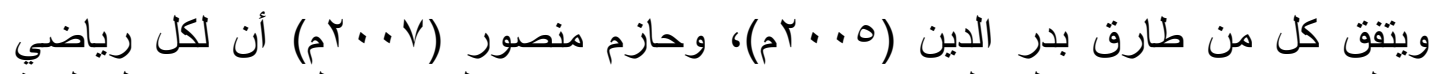

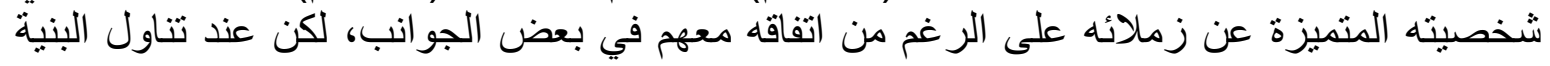




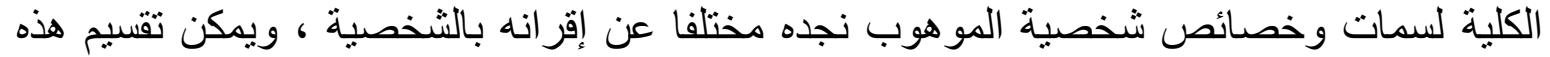

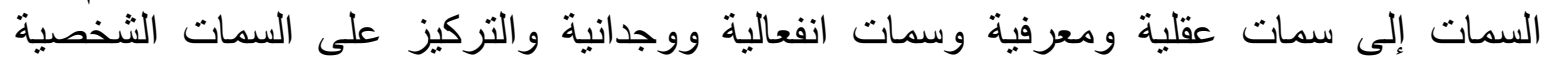

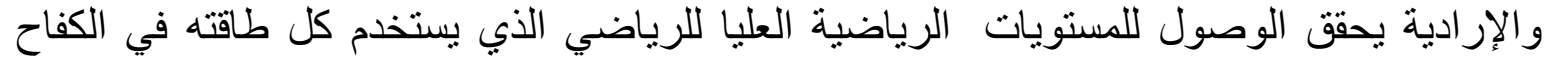

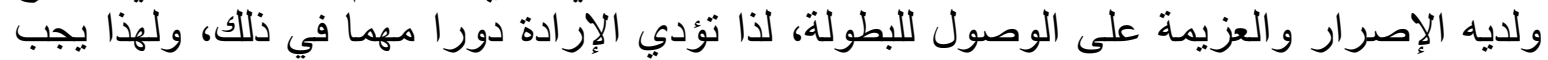

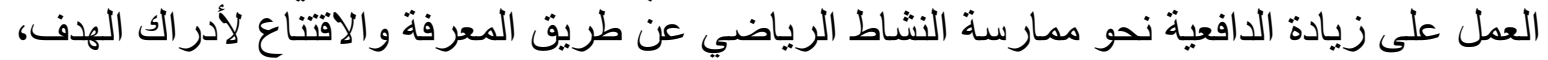

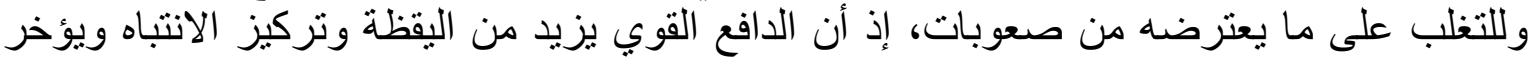

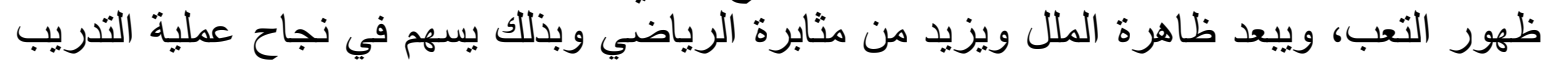
وتطبيق الذكاءات كاداه تعليمية وتدريبية وهذا يتفق مع در اسها

( (YV: I T) ،(OV:乏)

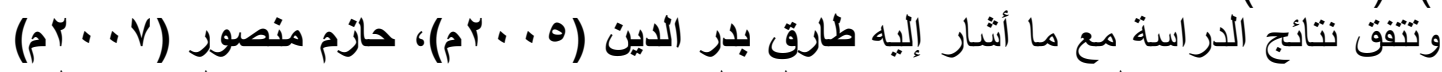

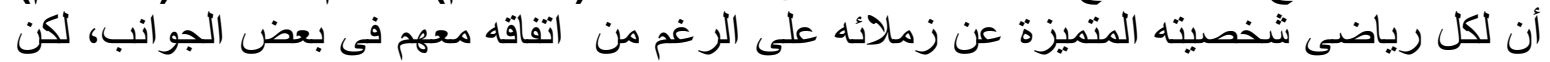

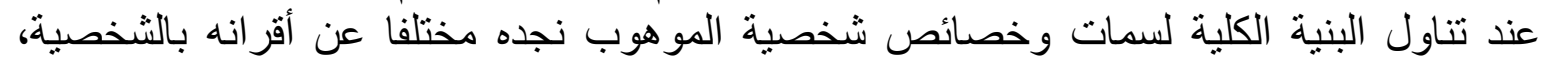

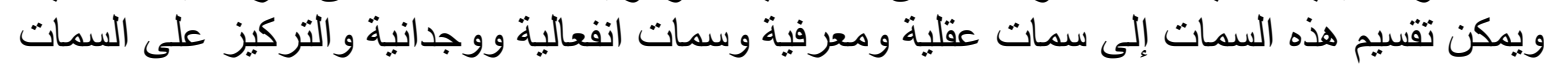

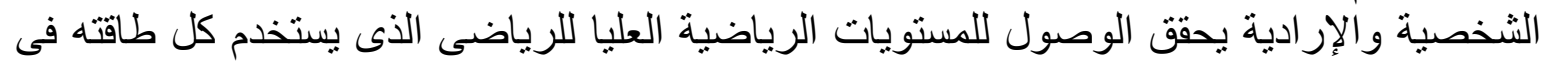

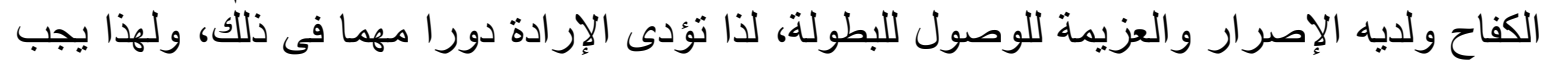

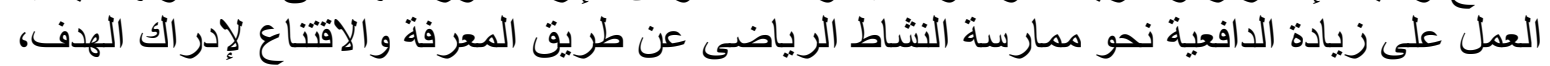

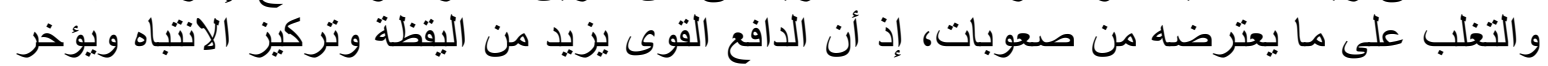

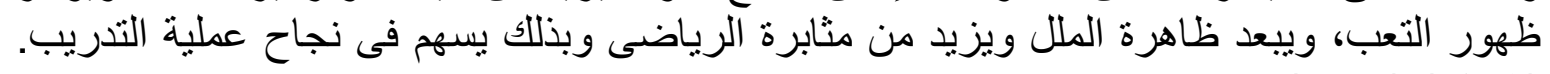
$(0 \vee: \varepsilon)(17: \wedge)$

وبهذ يتحقق الفرض الأول جزئيا والذي ينص على " توجد فروق ذات دلامة احصائية بين

خطوط اللعب فى مقياس الأكاعات المتعددة للاعبى كرة القدم "

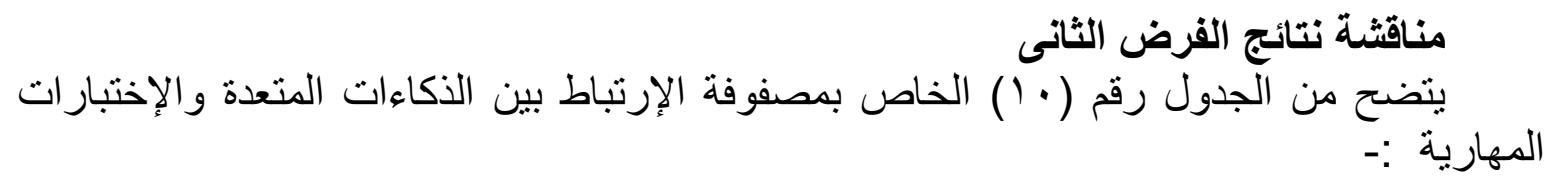

توجد علاقة طردية بين الذكاء الرياضى والذكاء اللغوى/ الثفوى حيث بلغت قيمة ( ر)

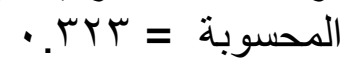
توجد علاقة طردية بين الذكاء المكانى و الذكاء الرياضى حيث بلغت قيمة ( ر ) المحسوبة =

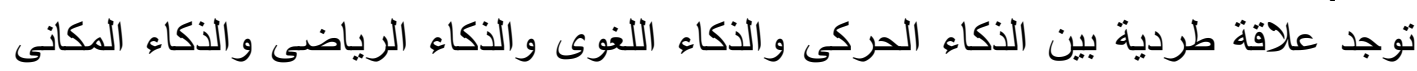

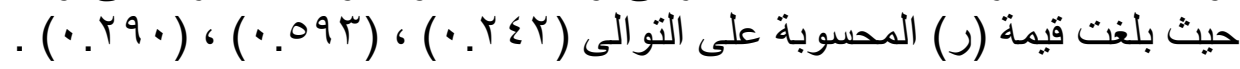

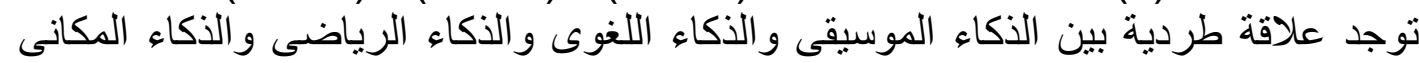

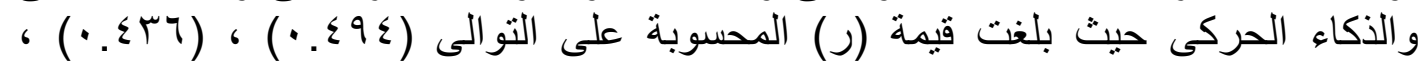

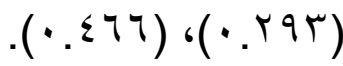

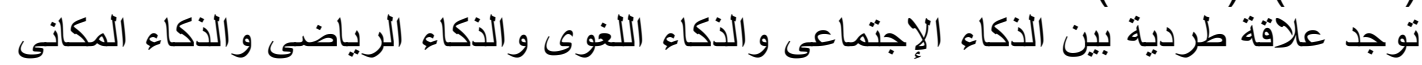

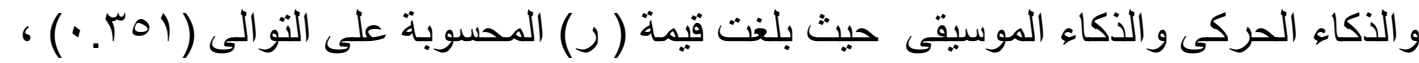

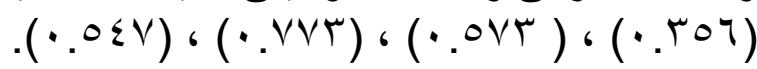

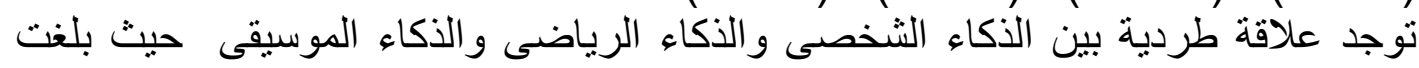

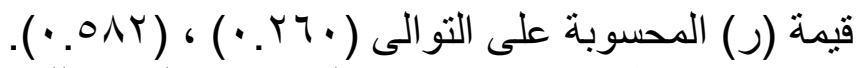

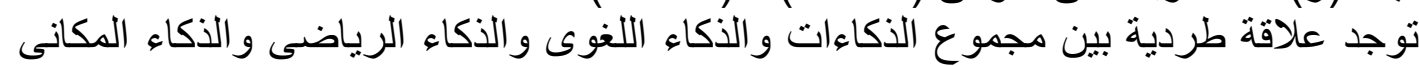

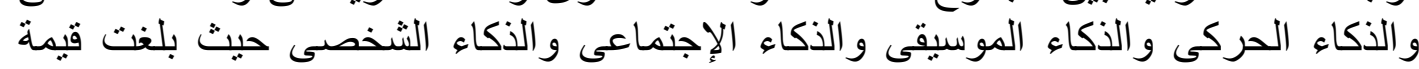




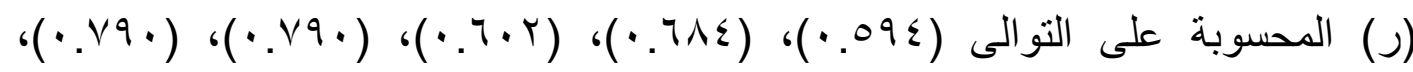

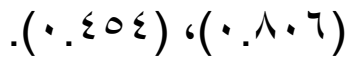

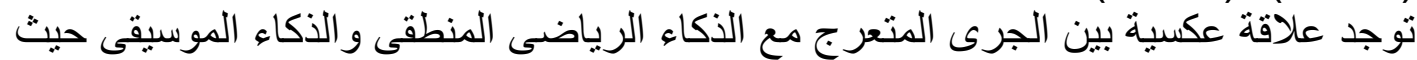

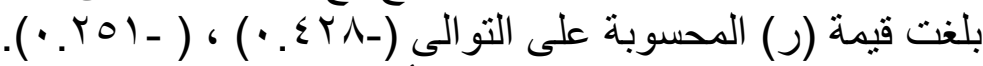

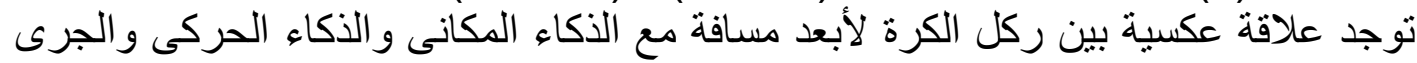

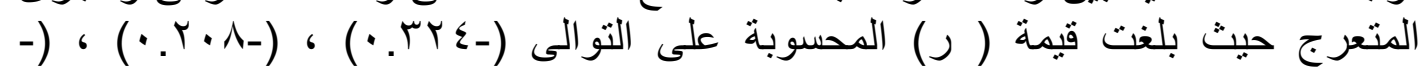
. (•. r توجد علاقة عكسية بين السيطرة على الكرة بباطن القدم مع الذكاء الثفوى والذكاء الدكانى الذاء

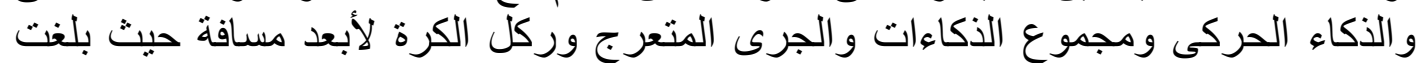

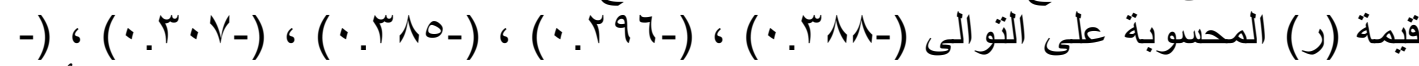

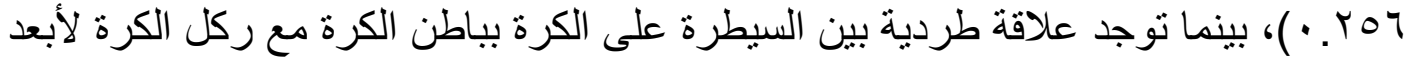

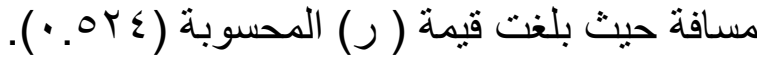

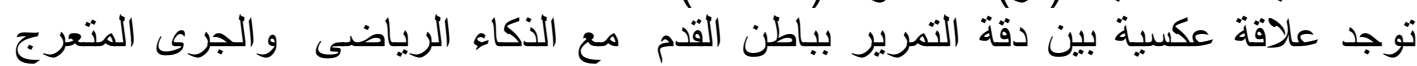

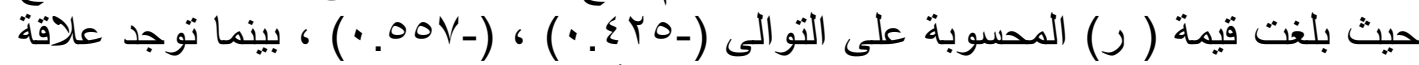

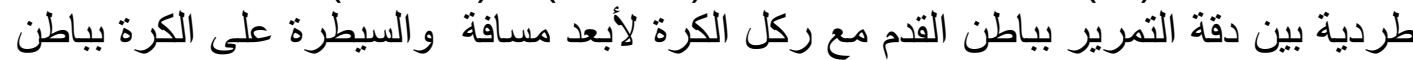

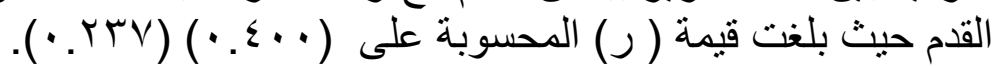

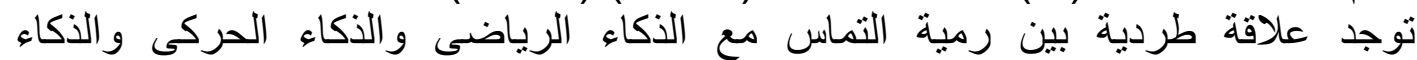

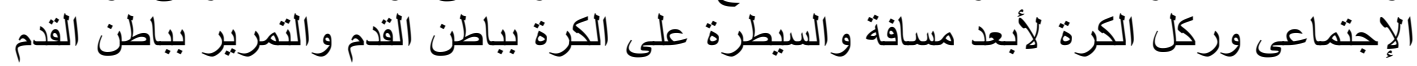

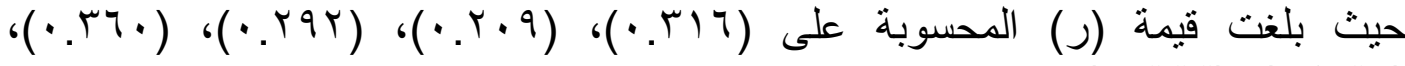

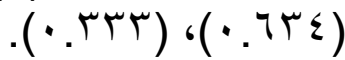
توجد علاقة عكسية بين رمية التماس مع الجرى المتعرج حيث بلغت قيمة ( ر) المحسوبة

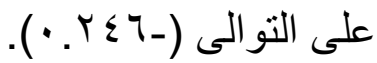

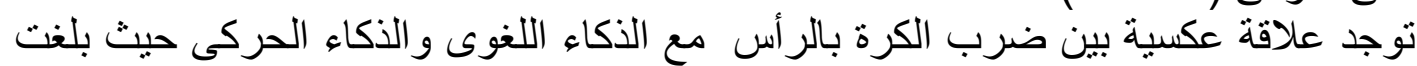

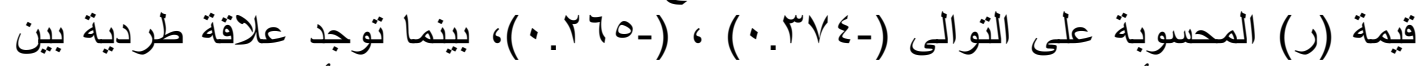

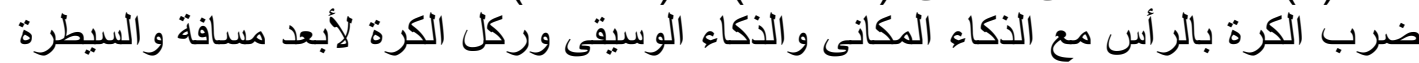

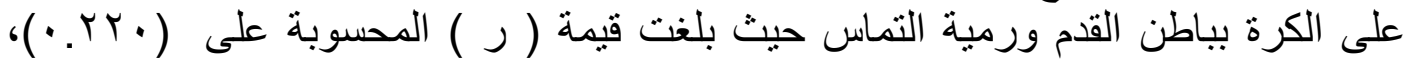

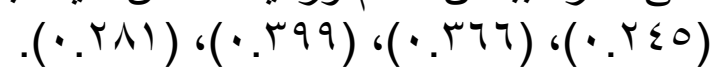

وبهذ يتحقق الفرض الثانى والذي ينص على " يوجد إرتباط ذات دلاية إحصائية بين

الأكاءات المتعددة والاختبارات المهارية قيد البحث. "

الاستخلاصات و التوصيات:

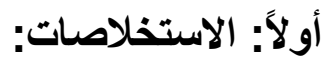

في حدود عينة البحث وفي ضوء النتائج التي تم التوصل إليها توصل الباحث إلى إلى

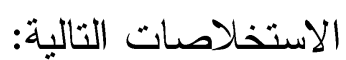

صلاحية مقياس الذكاءات المتعددة فى ضوء نظريه جاردنر للذكاءات المتعددة فى صورته

النهائية على لاعبى كرة القدم فى صورته النهائية.

وجود فروق ذات دلالة إحصائية فى مقياس الذكاءات المتعددة فى خطوط اللعب المختلفى فى لفى

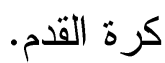




\section{في ضوء النتائج الاستخلاصات يوصي الباحث بما يلي:}

• إجر اء دراسة مقارنة للذكاءات المتعددة فى خطوط اللعب المختلفة للرجال والبات والسيدات في أعمار

\section{سنية مختلفة.}

در اسة فاعلية الذكاءات المتعددة وتطبيقها فى المو اقف التدريبية المختلفة للاعبى كرة القدم.

$$
\text { أولائمة المراجع: }
$$

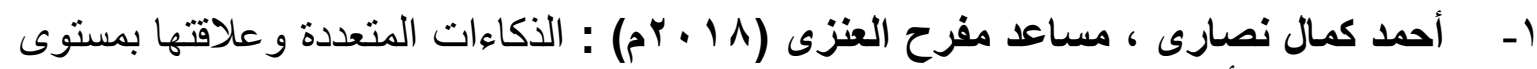

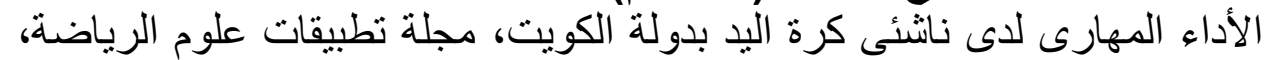

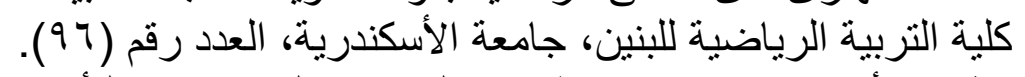

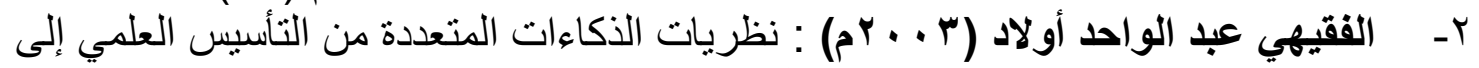

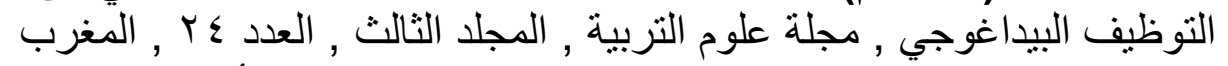

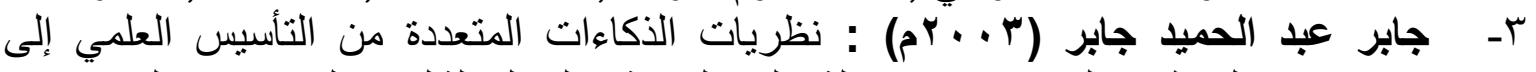

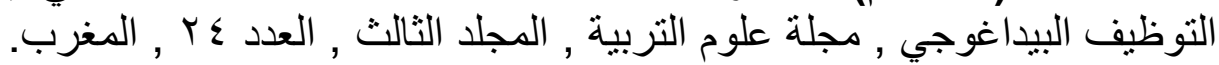

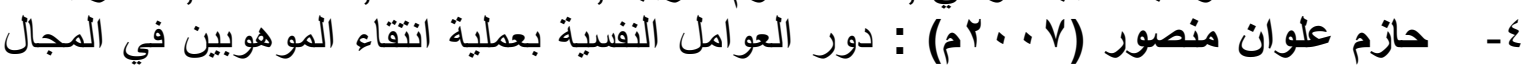

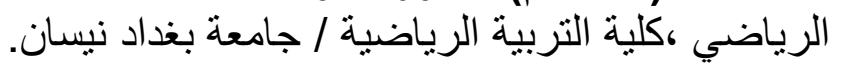

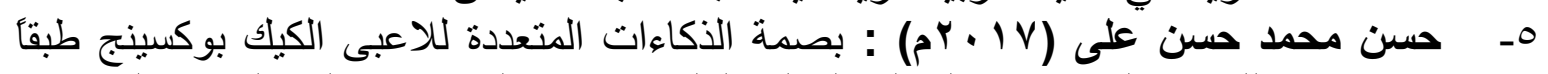

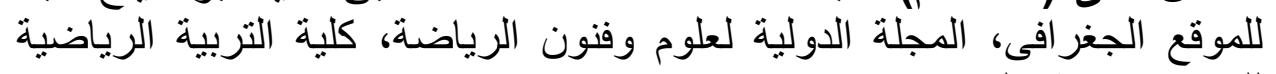

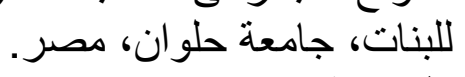

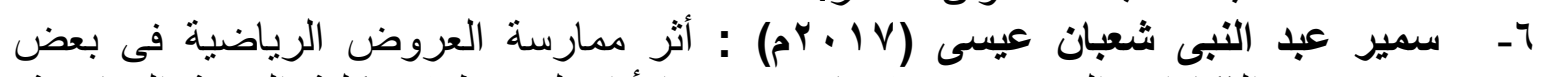

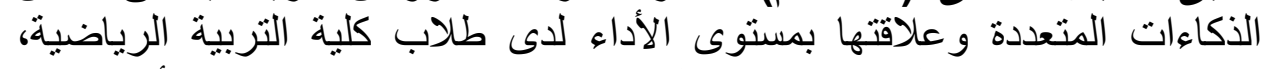

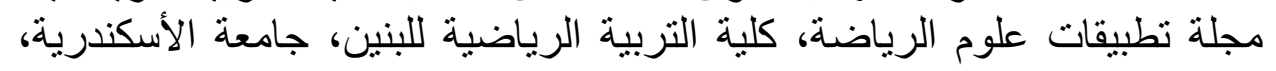

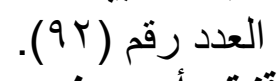

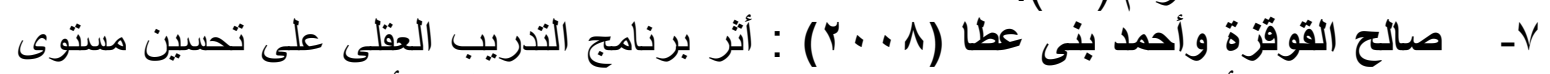

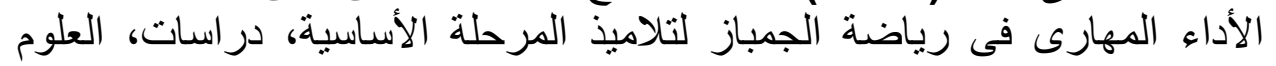

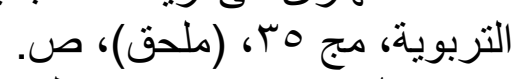

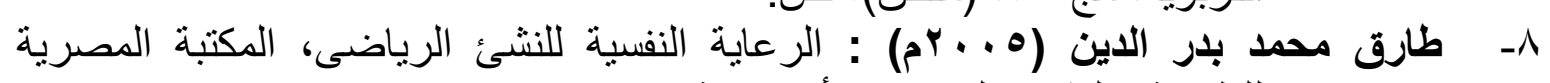
للطباعة والنشر و التوزيع، الأسكندرية.

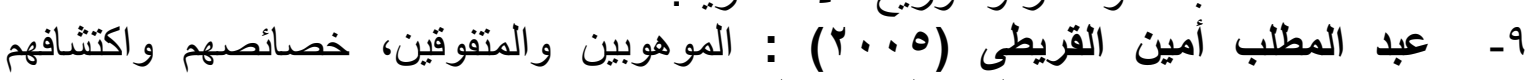

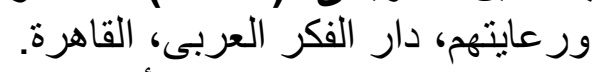

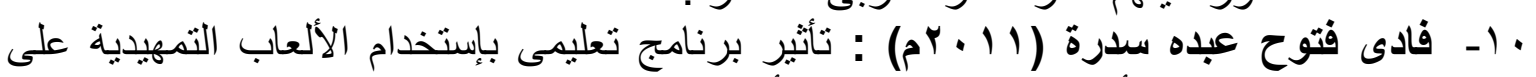

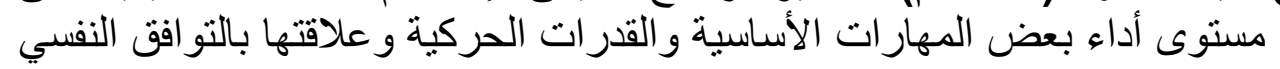

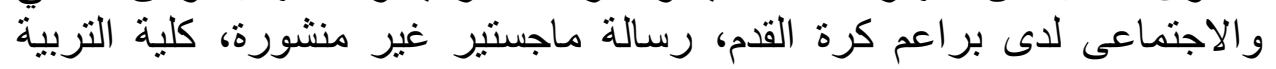

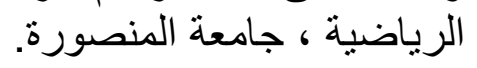

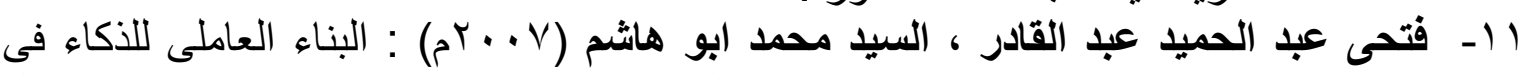

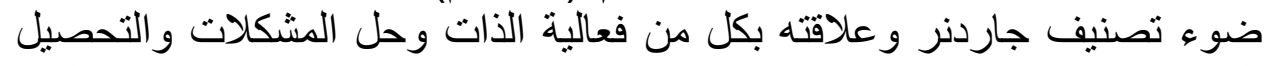
الدراسى لدى طلاب الجامعة ،مجلة كلية التربية ،جامعه الزقازية النيك ،يناير العدد 
r ا - مجدى حسن يوسف (؟ 1 بrم) : بصمه الذكاءات المتعددة لطلاب كلية التربية الرياضيه

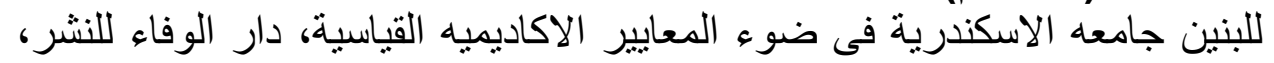

$$
\text { الاسكندرية. }
$$

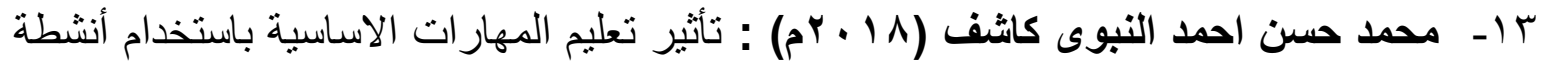

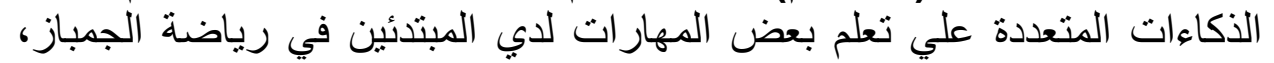

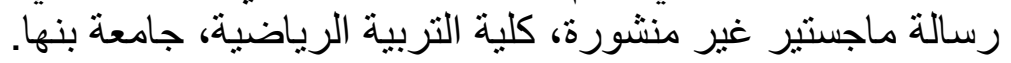

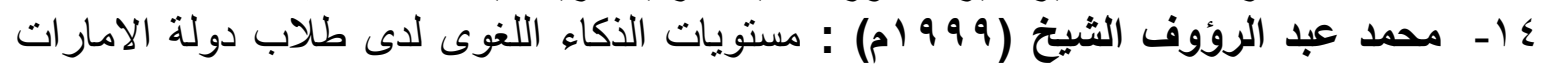

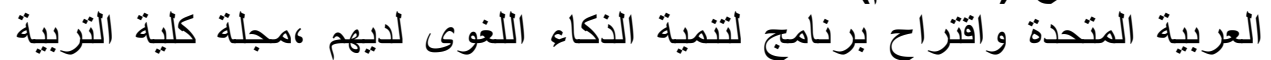

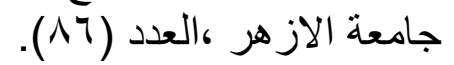

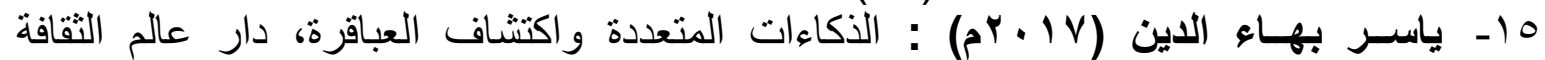

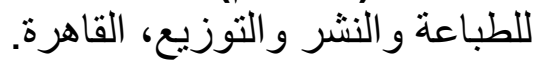

$$
\text { ثانيا: المراجع الاجنبية: }
$$

16- Alick, Dave. (1999): Integrating Multimedia and Multiple Intelligences to Ensure Quality learning in a high School Biology Classroom. EDUC 685-Multimedia Literacy.

17- Armstrong • (1994) Multiple Intelligence in The Classroom . Alexandria : Association for supervision and Curriculum Development . Arbor . Michigan . USA .

18- Armstrong, T.: (2000): Multiple Intelligences, Available From, www.Thomas Armstrong.com.

19- EL Ghany, M. A. A., BELAL,m. a. \& ABDEL Azim, N. R. M. (2010): Development and Mental Abilities for the Eiite of Junior Player of A Mentoring Program. International Journal of Information Studies, 2 (2), PP.97-13

20-

Gardner .H.(1983): Multiple intelligences, New. York :Basic Books.

21- Gardner .H.(1999) : intelligence Reframed:Multple intelligence for the 21st century.NewYORK:Basic BOOKS.

$22-$

$$
\begin{aligned}
& \text { مصادر الانترنت: }
\end{aligned}
$$

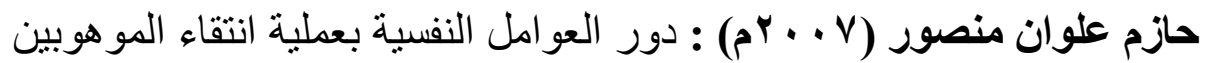

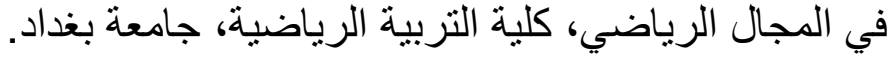

http://www.iraqacad.org/Lib/hazim/hazim3.htm 